\title{
in life expectancy between self-employed workers and paid employees when retirement pensioners: evidence from Spanish social security records Differences
}

\author{
Juan Manuel Pérez-Salamero González \\ Department of Financial Economics and Actuarial Science, University of \\ Valencia \\ Marta Regúlez-Castillo \\ Department of Applied Economics III. University of the Basque Country \\ (UPV/EHU) \\ Carlos Vidal-Meliá \\ Department of Financial Economics and Actuarial Science, University of \\ Valencia
}

Instituto Complutense
de
Análisis Económico

\begin{abstract}
The aim of this paper is to examine differences in life expectancy (LE) between selfemployed (SE) and paid employee (PE) workers when they become retirement pensioners, looking at levels of pension income using administrative data from Spanish social security records. We draw on the Continuous Sample of Working Lives (CSWL) to quantify changes in total life expectancy at ages 65 (LE65) and 75 (LE75) among retired men over the longest possible period covered by this data source: 2005-2018. These changes are broken down by pension regime and pension income level for three periods. Contrary to what has been observed in countries such as Italy, Finland and Japan, LE65 in Spain is slightly higher for the self-employed than for the paid employees when retirement pensioners. For 2005-2010, a gap in life expectancy of 0.23 years between SE and PE retirement pensioners is observed. This gap widens to 0.55 years for 2014-2018. A similar trend can be seen if pension income groups are considered. For 2005-2010, the gap in LE65 between pensioners in the lowest and the highest income groups is 1.20 years. This gap widens over time and reaches 1.51 years for 2014-2018. Although these differences are relatively small, they are statistically significant. According to our research the implications for policy on social security are evident: differences in life expectancy by socioeconomic status and pension regime should be taken into account for a variety of issues involving social security schemes, e.g. to establish the age of eligibility for retirement pensions and early access to benefits, to compute the annuity factors used to determine initial retirement benefits, and to value the liabilities taken on for retirement pensioners.
\end{abstract}

Keywords: Continuous Sample of Working Lives; Life expectancy; Paid employees; Retirement; Self-employed; Spain.

JEL Classification: C81, H55, I14, J26,

\section{ICAE Working Paper $n^{\circ} 2104$}

\section{February, 2021}




\title{
Differences in life expectancy between self-employed workers and paid employees when retirement pensioners: evidence from Spanish social security records ${ }^{i}$
}

\author{
Juan Manuel Pérez-Salamero González ${ }^{\mathrm{ii}}$, Marta Regúlez-Castillo ${ }^{\mathrm{iii}}$ and Carlos Vidal- \\ Meliá (corresponding author) ${ }^{\mathrm{iv}}$
}

\begin{abstract}
The aim of this paper is to examine differences in life expectancy (LE) between selfemployed (SE) and paid employee (PE) workers when they become retirement pensioners, looking at levels of pension income using administrative data from Spanish social security records. We draw on the Continuous Sample of Working Lives (CSWL) to quantify changes in total life expectancy at ages $65\left(\mathrm{LE}_{65}\right)$ and $75\left(\mathrm{LE}_{75}\right)$ among retired men over the longest possible period covered by this data source: 2005-2018. These changes are broken down by pension regime and pension income level for three periods. Contrary to what has been observed in countries such as Italy, Finland and Japan, $\mathrm{LE}_{65}$ in Spain is slightly higher for the self-employed than for the paid employees when retirement pensioners. For 2005-2010, a gap in life expectancy of 0.23 years between SE and PE retirement pensioners is observed. This gap widens to 0.55 years for 2014-2018. A similar trend can be seen if pension income groups are considered. For 2005-2010, the gap in LE 65 between pensioners in the lowest and the highest income groups is 1.20 years. This gap widens over time and reaches 1.51 years for 2014-2018. Although these differences are relatively small, they are statistically significant. According to our research the implications for policy on social security are evident: differences in life expectancy by socioeconomic status and pension regime should be taken into account for a variety of issues involving social security schemes, e.g. to establish the age of eligibility for retirement pensions and early access to benefits, to compute the annuity factors used to determine initial retirement benefits, and to value the liabilities taken on for retirement pensioners.
\end{abstract}

JEL: C81, H55, I14, J26.

KEYWORDS: Continuous Sample of Working Lives; Life expectancy; Paid employees; Retirement; Self-employed; Spain.

iFunding: The authors are grateful for the financial assistance received from the Spanish Ministry of the Economy and Competitiveness (Ministerio de Economía y Competitividad), projects ECO2015-65826-P, RTI2018-097087-B-100, the Generalidad Valenciana (Valencian Government), project AICO/2019/075, and the Basque Government, project IT1336-19.

Acknowledgements: The authors are especially grateful to David Atance del Olmo, who made an active contribution to previous versions, and to Peter Hall for his help with the English text.

Authors' contributions: data curation, J.M.P.-S.G.; formal analysis, M.R.-C. and C.V.-M.; investigation, J.M.P.S.G., M.R.-C. and C.V.-M.; methodology, C.V.-M.; software, J.M.P.-S.G. and M.R.-C.; writing-original draft, M.R.-C. and C.V.-M.; writing-review and editing, J.M.P.-S.G., M.R.-C. and C.V.-M. All authors have read and agreed to the published version of the manuscript.

ii Department of Financial Economics and Actuarial Science, University of Valencia, Avenida de los Naranjos s.n., 46022 Valencia (Spain). (e-mail: juan.perez-salamero@uv.es). ORCID Author ID: 0000-0001-7710-4869

iii Department of Applied Economics III. University of the Basque Country (UPV/EHU). Avda Lehendakari Aguirre 84, 48015 Bilbao (Spain). (e-mail: marta.regulez@,ehu.eus) ORCID Author ID: 0000-0002-4694-5144

iv Department of Financial Economics and Actuarial Science, University of Valencia, Avenida de los Naranjos s.n., 46022 Valencia (Spain). Instituto Complutense de Análisis Económico, Complutense University of Madrid, Spain (research affiliate) and Centre of Excellence in Population Ageing Research (CEPAR), UNSW, Sydney, Australia (research affiliate). (e-mail: carlos.vidal@uv.es). ORCID Author ID: 0000-0002-7227-5076. 


\section{1.-Introduction}

A significant inverse relationship in mortality risk across socioeconomic groups is almost always found among older individuals. The reviewed literature, which covers the UK (LSP, 2018 and 2020), the USA (Waldron, 2007; USA Bosley et al., 2018), Italy (Belloni et al., 2013; Lallo and Raitano, 2018), Canada (Wen et al., 2020), Germany (Kibele et al., 2013; Wenau et al., 2019; Tetzlaff et al., 2020), and the Netherlands (Kalwij et al., 2013), generally indicates that mortality gaps by socioeconomic status have not been constant over time and that inequalities in life expectancy as measured by socioeconomic status have increased in recent years. We are especially interested in differences in life expectancy between selfemployed workers and paid employees now in receipt of retirement pension (henceforth referred to as self-employed (SE) and paid employee (PE) pensioners).

Various studies on these differences have been published. According to Toivanen et al. (2016), differences in mortality between SE and PE individuals vary across industries and by gender depending on the type of self-employment. In Sweden they find that mortality is generally lower among those the SE who run limited liability companies than among PE.

Differences in life expectancy have been investigated less widely among pensioner groups than among active worker groups. The literature reviewed in this analysis shows mixed evidence. For some countries, such as Italy, Finland and Japan, SE pensioners have a lower life expectancy than other groups, especially civil servants and higher grade (and lower grade) non-manual workers. In Germany, however, SE pensioners have a higher life expectancy when work status is used as an indicator of socioeconomic position.

For Italy, the report by the Pensioners and Annuitants Working Group (2012) states that SE pensioners have a life expectancy that is higher than for the general population but lower than for other pensioner groups such as civil servants and private sector employees. This difference in life expectancy compared to the general population was still positive in 2009 and less than 1 year.

Polvinen et al. (2015), working on the case of Finland, find socioeconomic differences in cause-specific mortality after disability retirement due to different diseases. Among nondisability retirees, those in lower social classes clearly had the highest mortality rates. For both disability and non-disability retirees, the mortality rates for the self-employed were similar to those of manual workers. For non-disability retirees, SE beneficiaries had a lower life expectancy than higher- and lower-grade non-manual workers.

Luy et al. (2015) provide estimates of differences in life expectancy by education, household income, work status and vocational class in Germany. Of the main work-status groups and for men, manual workers exhibited the lowest life expectancy $\left(\mathrm{LE}_{40}=32.4, \mathrm{LE}_{65}=13.2\right)$, followed by public servants $\left(\mathrm{LE}_{40}=35.6, \mathrm{LE}_{65}=14.8\right)$, employed workers ( $\mathrm{LE}_{40}=36.1$, $\left.\mathrm{LE}_{65}=15.2\right)$ and self-employed workers $\left(\mathrm{LE}_{40}=36.6, \mathrm{LE}_{65}=15.3\right)$. Compared to manual workers, the extra life expectancy for public servants, employed workers and self-employed workers was therefore 3.2, 3.7 and 4.2 years at age 40 and 1.6, 2.0 and 2.1 years at age 65 respectively.

For the case of Japan, Tanaka et al. (2018) find that SE men showed higher crude mortality rates and a significantly higher multiple-adjusted hazard ratio than white-collar employees among both working and retired men. They also point out that the higher hazard of death among SE men was not significant among retired men.

Our paper deals with the case of Spain, given that as yet there is very little research on that country. The aim of the paper is to investigate the differences in life expectancy between SE and PE retirement pensioners by focusing especially on pension income levels, using administrative data from Spanish social security records. This is the first investigation to 
provide evidence on inequalities in life expectancy by pension income level and regime in Spain. We draw on the Continuous Sample of Working Lives to quantify changes in total life expectancy for retired men at ages $65\left(\mathrm{LE}_{65}\right)$ and $75\left(\mathrm{LE}_{75}\right)$ over the longest possible period covered by this data source: 2005-2018. These changes are broken down by pension regime and pension-income level for three periods. We use the level of initial pension income as our single indicator of the socioeconomic status of the retired population.

The social gradient of mortality is quantified by estimating changes in total life expectancy by pension income level at ages $65\left(\mathrm{LE}_{65}\right)$ and $75\left(\mathrm{LE}_{75}\right)$ over time. As a supplementary method, a comparison with the life expectancy of the Spanish population is also provided. Our approach enables us to accurately answer four basic research questions: Are there any differences in life expectancy between the SE and PE groups of retirement pensioners? Are there any differences between pension income groups? If so, are they statistically significant? Are there any differences in the trends in life expectancy between pension income groups and/or pension regime groups that lead to an increase or decrease in inequalities over time?

Contrary to what has been observed in countries such as Italy, Finland and Japan, in Spain $\mathrm{LE}_{65}$ is slightly higher for SE than for PE retirement pensioners. For 2005-2010, a life expectancy gap of 0.23 years between SE and PE retirement pensioners is reported. This gap widens to 0.55 years for 2014-2018. A similar trend can be observed when the pension income group is considered. For 2005-2010, the gap in $\mathrm{LE}_{65}$ between pensioners in the lowest and highest income groups is 1.20 years. This gap widens over time and reaches 1.51 years for 2014-2018. And although these inequalities appear relatively small, they are statistically significant.

The rest of the paper is structured as follows: Section 2 describes the population studied and the methodology used to analyse life expectancy among male pensioners in Spain. Section 3 presents the main results. Section 4 discusses some issues arising from the results. The paper ends with our concluding comments and an appendix, which describes the alternative approach used to build life expectancy confidence intervals and the associated results tables replicating those shown in Section 3.

\section{2.-Data and Methodology}

As already mentioned, we use a large administrative data set. The Continuous Sample of Working Lives (CSWL) ${ }^{1}$ is a random sample of around 1.2 million people, i.e. $4 \%$ of the reference population. It contains administrative data on the working lives that form the basis of this sample taken from Spanish social security records and comprises anonymized microdata with detailed information on individuals. It provides a unique data set with very rich information about employment histories and personal characteristics (Pérez-Salamero et al., 2017).

It should be stressed that ethics approval is not required to use this data set, since its use for scientific purposes has been regulated since its creation. Researchers can request versions of the CSWL by post, although a separate request has to be made for each version. Requests consist of a user profile describing the project being carried out and a document accepting the CSWL's conditions of use ${ }^{2}$.

The first wave of the CSWL covers people who had a financial link with the social security system in 2004 and provides the entire working histories (employment, unemployment and

\footnotetext{
${ }^{1}$ Also referred to by several authors as the Continuous Working Life Sample (CWLS) or the Continuous Survey of Working Lives (CSWL).

2 These are available at the following address:

http://www.seg-social.es/wps/portal/wss/internet/EstadisticasPresupuestosEstudios/Estadisticas/EST211
} 
retirement) of the sample population. It is updated every year by using selected variables to gather information from the social security system dating back to when computerized records began, and also from other administrative data sources that record additional information on individuals. As well as the details given by the institutions responsible for generating the CSWL, the data available to researchers runs from 2004 to 2018.

The sample reference population is defined as individuals who have had some connection (through contributions, pensions or unemployment benefits) to the social security system at any time during the year of reference. Individuals are selected from the reference population each year according to whether their identification codes contain certain randomly-generated figures in the correct positions. Each year the individuals who figured in the previous version of the CSWL and continue to have a relationship with social security remain in the selection, and further individuals are incorporated if they meet the requirement of having the right identification codes for inclusion. The detailed information available on the individuals selected includes work trajectories from 1967 and contribution bases from 1980 and/or pensions from 1996, as long as they figure in social security administrative records. Those individuals who for some reason have no connection with social security in a particular year do not appear in the CSWL. When individuals are added to the sample as replacements, retrospective information on them is also available. Individuals lost in a certain year will enter the sample again if they become administratively active in subsequent years. Public employees are not included in these data.

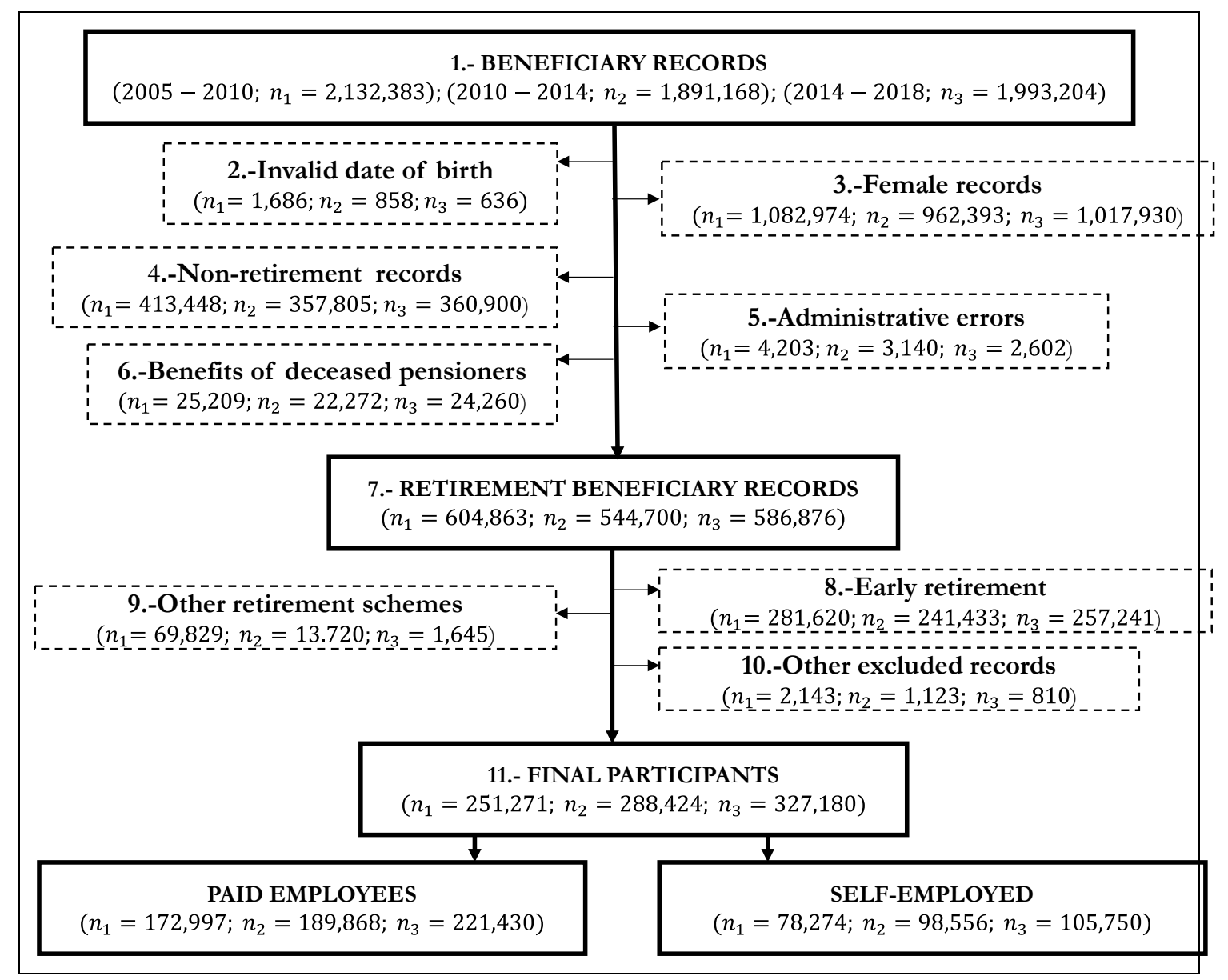

Figure 1: Flow chart of participants/records excluded from the present study, CSWL, 2005-2018

As can be seen in Figure 1, a considerable amount of time and effort went into preparing the administrative data for the analysis reported here. In our study the first wave (2004) has been 
excluded because it is not possible to determine the actuarial age of the beneficiaries and the codes for type of benefit were not properly recorded.

\section{1.-Variables and population studied}

The following variables are available from the CSWL data: month and year in which the pension was first paid and ended (if ended), regulating base used to calculate the amount of benefit, years contributed under each pension regime, benefit type (old age pension, early retirement, disability insurance, survivor benefits and other) and gender.

As shown below, the design of the Spanish pension system means that retirement benefits in the PE regime (general regime) are closely related to lifetime earnings. Benefits for retirement pensioners in the SE regime, on the other hand, cannot be related to lifetime earnings with any precision.

Table 1 shows the exposures in person-years and number of deaths by time period (absolute values and percentages) for "hypothetical pensioner income levels" and periods analysed. To analyse the data we group the records into four pension income levels $\left(B_{m}\right)$ : "1-Low"; "2Medium-Low", "3-Medium-High" and "4-High". We ruled out using benefit level quartiles because, given the features of the sample, some individuals could change quartile due to the number of new entrants in each wave.

We assign pensioners to each group according to the minimum (Min) and maximum (Max) benefits in force at the time of their retirement: Low: $B_{1} \leq$ Min; Medium-Low: Min $<B_{2} \leq$ $(0.5 \mathrm{Max}+0.33 \mathrm{Min})$; Medium-High: $(0.5 \mathrm{Max}+0.33 \mathrm{Min})<B_{3} \leq 0.75 \mathrm{Max}$; and High: $B_{4}>$ $0.75 \mathrm{Max}$. Based on the benefit levels in force, the ranges vary over the years reported, e.g. between $€ 36,121.82$ (Max) and $€ 8,727.60$ (Min) per year in 2018. For the 2018 calendar year, the pension income level annual breakpoints for the four intervals are $€ 8,727.60, € 20,679.19$ and $€ 27,091.37$.

\begin{tabular}{|c|c|c|c|c|c|c|}
\hline \multicolumn{2}{|c|}{ Periods/Items/groups } & \multirow{2}{*}{$\begin{array}{l}\text { Low } \\
40,604\end{array}$} & \multirow{2}{*}{$\begin{array}{r}\text { Med-Low } \\
115,873\end{array}$} & \multirow{2}{*}{$\begin{array}{r}\text { Med-High } \\
27,025 \\
\end{array}$} & \multirow{2}{*}{$\begin{array}{l}\text { High } \\
28,911\end{array}$} & \multirow{2}{*}{$\begin{array}{l}\text { Total } \\
212,412\end{array}$} \\
\hline \multirow{4}{*}{ 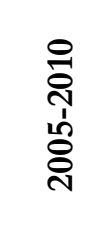 } & Exposures & & & & & \\
\hline & \% Exposures & 19.12 & 54.55 & 12.72 & 13.61 & 100 \\
\hline & Deaths & 2,449 & 4,891 & 957 & 793 & 9,090 \\
\hline & $\%$ Deaths & 26.94 & 53.81 & 10.53 & 8.72 & 100 \\
\hline \multirow{4}{*}{ 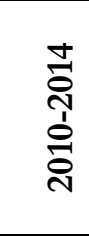 } & Exposures & 37,239 & 135,833 & 25,022 & 38,101 & 236,194 \\
\hline & $\%$ Exposures & 15.77 & 57.51 & 10.59 & 16.13 & 100 \\
\hline & Deaths & 2,160 & 5,788 & 930 & 894 & 9,772 \\
\hline & $\%$ Deaths & 22.10 & 59.23 & 9.52 & 9.15 & 100 \\
\hline \multirow{4}{*}{ 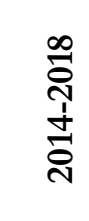 } & Exposures & 38,717 & 149,875 & 27,515 & 51,177 & 267,284 \\
\hline & $\%$ Exposures & 14.49 & 56.07 & 10.29 & 19.15 & 100 \\
\hline & Deaths & 2,025 & 6,596 & 1,083 & 1,170 & 10,874 \\
\hline & $\%$ Deaths & 18.62 & 60.66 & 9.96 & 10.76 & 100 \\
\hline \multicolumn{7}{|c|}{ Source: Own work } \\
\hline
\end{tabular}

If the initial amount of retirement benefit determined in accordance with the rules in force falls below the legislated minimum amount, then a complement is added to it. However, there are certain limitations governing receipt of that complement depending on overall 
earnings levels. Consequently, the benefit could be lower than the "official" minimum benefit in operation.

In order to receive retirement benefit, individuals have to pay into the system for at least 15 years in total, including at least two years' contributions in the last 15 years. The resulting initial monthly pension distributed over 14 payments per year is the product of two main factors: the total replacement rate stipulated and the regulatory base calculated. The total replacement rate is the product of two rates: the replacement rate according to retirement age and years contributed, and the replacement rate according to the number of years contributed. The regulatory base is calculated using the last " $n$ " years of contributions before retirement and the amounts are indexed, only before month 24, using the Spanish retail price index (RPI). The value of " $n$ " depends on the calendar year in which the worker reaches retirement. For 2013 and before it was 15 years, but the period for calculating the regulatory base is currently being extended from 15 to 25 years over a transitional period of 10 years by increasing it by one year per annum from 2013 to 2022 .

In practice, a retirement pensioner can receive a benefit that is higher (up to $26 \%$ more) than the "official" maximum benefit due to the maternity supplement and/or additional amounts for delaying retirement beyond the statutory age. The maximum pension cannot exceed the ceiling stipulated for the contribution base. In 2018 this was $€ 45,664$.

Traditionally, pensions in payment were indexed using the RPI until 2013, but a new index for updating pensions in payment was introduced in 2014: the new revaluation of pensions index (IRP in Spanish). This was based on the financial balance of pensions and social reform to ensure the system's financial sustainability. The new index was suspended in 2018. Pensions in payment were increased by 1.6\% in both 2018 and 2019 in line with the RPI, whereas they would have only increased by $0.25 \%$ had the IRP formula been applied ${ }^{3}$.

The contributory system in Spain is structured into different "regimes" or schemes, each of which covers a group of workers of a particular type. The general system ${ }^{4}$ is the basic core and includes all employees over 16 not included in another "special system." In general terms it covers all paid employees (PE). We also include retirement pensioners who belong to the special system for the self-employed (SE), although the pension rules could make their benefits a poor proxy for lifetime income (Figure 1, box 11). The contribution base in this scheme for the SE is chosen annually by the worker, an amount somewhere between the minimum and maximum bases in force each year.

In our study the initial population comprises (true) retirement pensioners whose retirement age was 65 (the ordinary retirement age ${ }^{5}$ ) or over and who were in the general or SE schemes. Figure 1 in the introduction to this section shows a flow chart of the participants/records excluded from the present study.

Due to the different rules for both collectives of retirement pensioners, it would be a good idea to detail the exposures and deaths for both by pension income level: Table 2 for SE retirement beneficiaries and Table 3 for PE retirees.

As Table 2 shows, the data for the medium-high and high pension income groups include very few individuals. There are low exposures and zero deaths at many ages, so the estimate

\footnotetext{
3 The sustainability factor, which was supposed to apply from January 2019 to adjust initial pensions on the basis of changes in life expectancy, was also suspended until 2023. A commission will determine how to proceed with both the sustainability factor beyond 2023 and the new indexation mechanism.

4 The general system accounts for $73 \%$ of pensions and $78 \%$ of contributors (March 2020).

5 Until 31 December 2012 the statutory retirement age was 65. From 2027 onwards there will be two standard retirement ages: 65 with 38.5 years' contributions and 67 with 37 years' contributions. The shift from 65 to 67 is being made gradually between 2013 and 2027.
} 
of life expectancy is highly unreliable, and for this reason both these pension income groups have been ruled out. The exclusions, only for the analysis of the pension income groups, represent $2.53 \%, 2.58 \%$ and $3.24 \%$ of exposures for periods 1,2 and 3 respectively.

\begin{tabular}{|c|c|c|c|c|c|c|}
\hline \multicolumn{2}{|c|}{ Periods/Items/groups } & Low & Med-Low & Med-High & High & Total \\
\hline \multirow{4}{*}{ 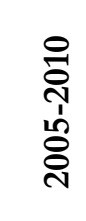 } & Exposures & 18,459 & 45,379 & 895 & 763 & 65,495 \\
\hline & \% Exposures & 28.18 & 69.29 & 1.37 & 1.16 & 100 \\
\hline & Deaths & 1,317 & 1,523 & 20 & 13 & 2,873 \\
\hline & $\%$ Deaths & 45.84 & 53.01 & 0.70 & 0.45 & 100 \\
\hline \multirow{4}{*}{ 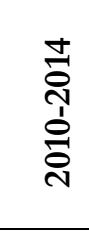 } & Exposures & 17,123 & 61,348 & 1,096 & 980 & 80,546 \\
\hline & \% Exposures & 21.26 & 76.16 & 1.36 & 1.22 & 100 \\
\hline & Deaths & 1,190 & 2,256 & 30 & 20 & 3,496 \\
\hline & $\%$ Deaths & 34.04 & 64.53 & 0.86 & 0.57 & 100 \\
\hline \multirow{4}{*}{ 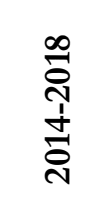 } & Exposures & 17,156 & 66,515 & 1,543 & 1,262 & 86,474 \\
\hline & \% Exposures & 19.84 & 76.92 & 1.78 & 1.46 & 100 \\
\hline & Deaths & 1,017 & 2,598 & 45 & 33 & 3,693 \\
\hline & $\%$ Deaths & 27.54 & 70.35 & 1.22 & 0.89 & 100 \\
\hline \multicolumn{7}{|c|}{ Source: Own work } \\
\hline
\end{tabular}

Table 3 contains a high enough number of exposures and deaths for all pension income groups.

\begin{tabular}{|c|c|c|c|c|c|c|}
\hline \multicolumn{2}{|c|}{ Periods/Items/groups } & Low & Med-Low & Med-High & High & Total \\
\hline \multirow{4}{*}{ 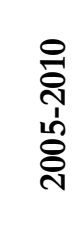 } & Exposures & 22,146 & 70,494 & 26,130 & 28,148 & 146,917 \\
\hline & $\%$ Exposures & 15.07 & 47.98 & 17.79 & 19.16 & 100 \\
\hline & Deaths & 1,132 & 3,368 & 937 & 780 & 6,217 \\
\hline & $\%$ Deaths & 18.21 & 54.17 & 15.07 & 12.55 & 100 \\
\hline \multirow{4}{*}{ 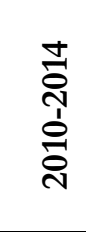 } & Exposures & 20,116 & 74,485 & 23,927 & 37,121 & 155,648 \\
\hline & $\%$ Exposures & 12.92 & 47.85 & 15.37 & 23.85 & 100 \\
\hline & Deaths & 970 & 3,532 & 900 & 874 & 6,276 \\
\hline & $\%$ Deaths & 15.46 & 56.28 & 14.34 & 13.93 & 100 \\
\hline \multirow{4}{*}{ 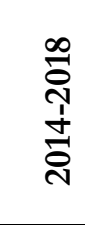 } & Exposures & 21,562 & 83,361 & 25,973 & 49,915 & 180,810 \\
\hline & $\%$ Exposures & 11.92 & 46.10 & 14.36 & 27.61 & 100 \\
\hline & Deaths & 1,008 & 3,998 & 1,038 & 1,137 & 7,181 \\
\hline & $\%$ Deaths & 14.04 & 55.67 & 14.45 & 15.83 & 100 \\
\hline \multicolumn{7}{|c|}{ Source: Own work } \\
\hline
\end{tabular}

As can be seen from Tables 2 and 3, the total number of pensioners has significantly increased in both groups. The total number of SE beneficiaries increased by $32 \%$ over ten years and total PE beneficiaries increased by $23 \%$. The main differences are concentrated in 
the high and medium-high groups. These differences show how the number of elderly people has increased over time in Spain.

Because of lower labour force participation rates among female cohorts and the fact that women's careers tend to be shorter (in terms of years of employment) and they often work less intensively than men, mainly due to their family role and commitments, the pension income level is not a suitable indicator for women's working-life income. Therefore, the focus of our analysis in this research is the social gradient in male mortality (Figure 1, box 3).

It is a stylized fact that mortality among disabled people is far higher than among the general population, so combining the two populations (true retirement pensioners and disabled beneficiaries) could result in seriously misleading implications when it comes to accurately determining the social gradient in mortality. Beneficiaries with pension reclassification ${ }^{6}$ are therefore also excluded (Figure 1, box 4).

Early retirement is possible four years before the legal retirement age in cases of involuntary unemployment with 33 years' contributions, and two years before in cases of voluntary unemployment with 35 years' contributions. The actuarial reduction on pension benefits for early retirement ranges from $2 \%$ to $1.5 \%$ per quarter depending on the number of years contributed. Given that poor health is an important reason for early retirement and is also a well-established risk factor for mortality (Wu et al., 2016), pensioners who access benefits before the statutory retirement age are also excluded (Figure 1, box 8).

\section{2.-Methodology}

We decided to study the social gradient in mortality by estimating changes in total life expectancy by pension income level and pension regime at age 65 over time. We use the Mort1Dsmooth function in the MortalitySmooth $\mathrm{R}_{\text {package }}{ }^{7}$ - which is specifically designed for mortality research - to construct complete period life tables from age 65 to age 101 and to calculate life expectancy at ages $65\left(\mathrm{LE}_{65}\right)$ and $75\left(\mathrm{LE}_{75}\right)$ for three different periods: $\mathrm{P}_{1}$ : 2005-2010, $\mathrm{P}_{2}: 2010-2014$ and $\mathrm{P}_{3}: 2014-2018$. The first period covers five years, whereas the second and third both cover four years. The actual number of deaths and the risk exposure used to calculate the crude annual death rate come from the CSWL (Tables 1 to 3). Data above age 101 are unreliable because there are small exposures and the reporting of deaths is questionable for very old ages.

Mort1Dsmooth smooths one-dimensional Poisson counts (deaths) with P-splines. It returns various settings and measures ${ }^{8}$. Once graduated death rates are obtained, it is easy to construct complete period life tables from age 65 to age 101 and calculate life expectancy at various ages. Life expectancy, $\mathrm{LE}_{\mathrm{x}}$, is an estimate of the average number of additional years that a cohort of a given age, $\mathrm{x}$, can expect to live. This measure of remaining life is the ratio between the total number of person-years lived by the cohort from age $\mathrm{x}$ until all members of the cohort have died $\left(T_{x}\right)$ and the number of persons alive at age $\mathrm{x}\left(\mathrm{l}_{\mathrm{x}}\right)$. For complete $\mathrm{LE}_{\mathrm{x}}$ half a year is added.

\footnotetext{
${ }^{6}$ In many countries when a disability-pension beneficiary reaches statutory retirement age, their disability benefits are classified as retirement benefits. This is known as "pension reclassification".

7 We also used an R Package for Mortality Rates Graduation by Discrete Beta Kernel Techniques (Mazza and Punzo, 2015). The results are very similar. Their package uses univariate and bivariate adaptive discrete beta kernel estimators. The number of deaths follows a binomial distribution.

${ }^{8}$ Full details in Camarda (2012).
} 
According to Li (2015), one important purpose of measuring mortality is to detect differences between populations. To that end, deterministic life tables could specify whether a life-table variable for one population is bigger than the same variable for another, while a probabilistic life table can further test whether such differences are statistically significant or appear merely by random chance.

Following Chiang (1984), an observed $\mathrm{LE}_{\mathrm{x}}$ is a sample mean of future lifetime. Therefore, statistical tests based on normal distribution can be used to draw inferences by comparing $\mathrm{LE}$ between two groups for a given age and period $\left(\mathrm{LE}_{\mathrm{x}, \mathrm{P}}^{\mathrm{P}}\right)$. Here we are interested in testing whether there is a significant positive difference in $\mathrm{LE}_{\mathrm{X}, \mathrm{P}}^{\mathrm{m}}$ between two pensioner income groups (two pensioner income regimes or periods), one with a higher PI than the other.

Under the null hypotheses this difference will be zero and under the alternative it will be positive, so it is a one-tailed test. The statistic to be used, the $z$ score, is the ratio of the difference in LE between the groups $\left(\mathrm{DLE}_{\mathrm{x}, \mathrm{P}}^{\mathrm{m}_{\mathrm{i}}-\mathrm{m}_{\mathrm{j}}}\right.$ ) to the standard error of that difference $\operatorname{Se}\left(D_{L E} \mathrm{~m}_{\mathrm{X}, \mathrm{P}}^{\mathrm{m}_{\mathrm{i}}-\mathrm{m}_{\mathrm{j}}}\right)$, which is computed as the square root of the sum of the variances of the corresponding $\mathrm{LE}_{\mathrm{x}}$ for each group, $\mathrm{VLE}_{\mathrm{x}, \mathrm{P}}^{\mathrm{m}_{\mathrm{i}}}$ and $\mathrm{VLE}_{\mathrm{x}, \mathrm{P}}^{\mathrm{m}_{\mathrm{j}}}$ respectively.

$$
\mathrm{z}_{\mathrm{x}, \mathrm{P}}^{\mathrm{m}_{\mathrm{i}}-\mathrm{m}_{\mathrm{j}}}=\frac{\mathrm{DLE}_{\mathrm{x}, \mathrm{P}}^{\mathrm{m}_{\mathrm{i}}-\mathrm{m}_{\mathrm{j}}}}{\operatorname{Se}\left(\mathrm{DLE}_{\mathrm{x}, \mathrm{P}}^{\mathrm{m}_{\mathrm{i}}-\mathrm{m}_{\mathrm{j}}}\right)}=\frac{\operatorname{DLE}_{\mathrm{x}, \mathrm{P}}^{\mathrm{m}_{\mathrm{i}}-\mathrm{m}_{\mathrm{j}}}}{\sqrt{\operatorname{VLE}_{\mathrm{x}, \mathrm{P}}^{\mathrm{m}_{\mathrm{i}}}+\mathrm{VLE}_{\mathrm{x}, \mathrm{P}}^{\mathrm{m}_{\mathrm{j}}}}}
$$

By analogy with the development made by Chiang (1984), the standard error for life expectancy at age $\mathrm{x}, \operatorname{Se}\left(\mathrm{LE}_{\mathrm{x}, \mathrm{P}}^{\mathrm{m}}\right)$, can be calculated as follows ${ }^{9}$ :

$$
\operatorname{Se}\left(\operatorname{LE}_{\mathrm{x}, \mathrm{P}}^{\mathrm{m}}\right)=\sqrt{\sum_{\mathrm{k}=0}^{\mathrm{w}-1-\mathrm{x}}\left[\left({ }_{\mathrm{k}} \mathrm{p}_{\mathrm{x}, \mathrm{P}}^{\mathrm{m}}\right)^{2} \cdot\left(\mathrm{LE}_{\mathrm{x}+\mathrm{k}+1, \mathrm{P}}^{\mathrm{m}}\right)^{2} \cdot \frac{\left(\mathrm{q}_{\mathrm{x}+\mathrm{k}, \mathrm{P}}^{\mathrm{m}}\right)^{2} \cdot\left(1-\mathrm{q}_{\mathrm{x}+\mathrm{k}, \mathrm{P}}^{\mathrm{m}}\right)}{\mathrm{D}_{\mathrm{x}+\mathrm{k}, \mathrm{P}}^{\mathrm{m}}}\right]}
$$

where ${ }_{\mathrm{k}} \mathrm{p}_{\mathrm{x}, \mathrm{P}}^{\mathrm{m}}$ is the is the probability of surviving from age $x$ to age $\mathrm{x}+\mathrm{k}, \mathrm{q}_{\mathrm{x}+\mathrm{k}, \mathrm{P}}^{\mathrm{m}}$ is the probability that an individual aged $\mathrm{x}+\mathrm{k}$ will die within the year, $\mathrm{LE}_{\mathrm{x}+\mathrm{k}+1, \mathrm{P}}^{\mathrm{P}}$ is life expectancy at age $x+k$, and $D_{x+k, P}^{m}$ is the number of deaths at age $x+k$. These elements refer to period $\mathrm{P}$ and PI group $\mathrm{m}$.

At a given level of significance $\alpha$, the null hypothesis is rejected if the sample value of the statistic $\mathrm{z}_{\mathrm{x}, \mathrm{P}} \mathrm{m}_{\mathrm{j}}-\mathrm{m}_{\mathrm{j}}$ is greater than the critical value in the normal distribution corresponding to that level of significance $(2.33$ at $1 \%, 1.64$ at $5 \%$, and 1.28 at $10 \%)$. If that is the case, there is statistically significant evidence that $\mathrm{LE}_{\mathrm{x}, \mathrm{P}}^{\mathrm{m}}$ is greater for the higher PI group than for the other.

Finally, it is worth indicating that $95 \%$ confidence intervals (CIs) of $\mathrm{LE}_{\mathrm{x}, \mathrm{P}}^{\mathrm{m}}$ are determined by:

$$
95 \% \operatorname{CI}\left(\mathrm{LE}_{\mathrm{x}, \mathrm{P}}^{\mathrm{m}}\right)=\mathrm{LE}_{\mathrm{x}, \mathrm{P}}^{\mathrm{m}} \pm 1.96 \cdot \operatorname{Se}\left(\mathrm{LE}_{\mathrm{x}, \mathrm{P}}^{\mathrm{m}}\right)
$$

\footnotetext{
9 According to Scherbov and Ediev (2011), Chiang's method can be used without significant problems with population sizes from about 10,000 upwards.
} 


\section{3.-Results}

Results are going to be mainly shown by means of several figures and tables.

Figure 2, which contains two graphs, shows 95\% confidence intervals (CIs) LE 65 (Graph 1) and $\mathrm{LE}_{75}$ (Graph 2) for both groups of pensioners (self-employed (SE) and paid employees $(\mathrm{PE})$ ) and total and all three periods analyzed. Contrary to what has been observed in some countries such as Italy and Japan, $\mathrm{LE}_{65}$ is slightly higher for SE than for PE retirement pensioners. For 2005-2010, a gap in life expectancy of 0.23 years between SE and PE retirement pensioners is reported. This deviation reaches 0.55 years in 2014-2018. For LE 75 (Graph 2) absolute differences are fairly stable (at around 0.14 years).

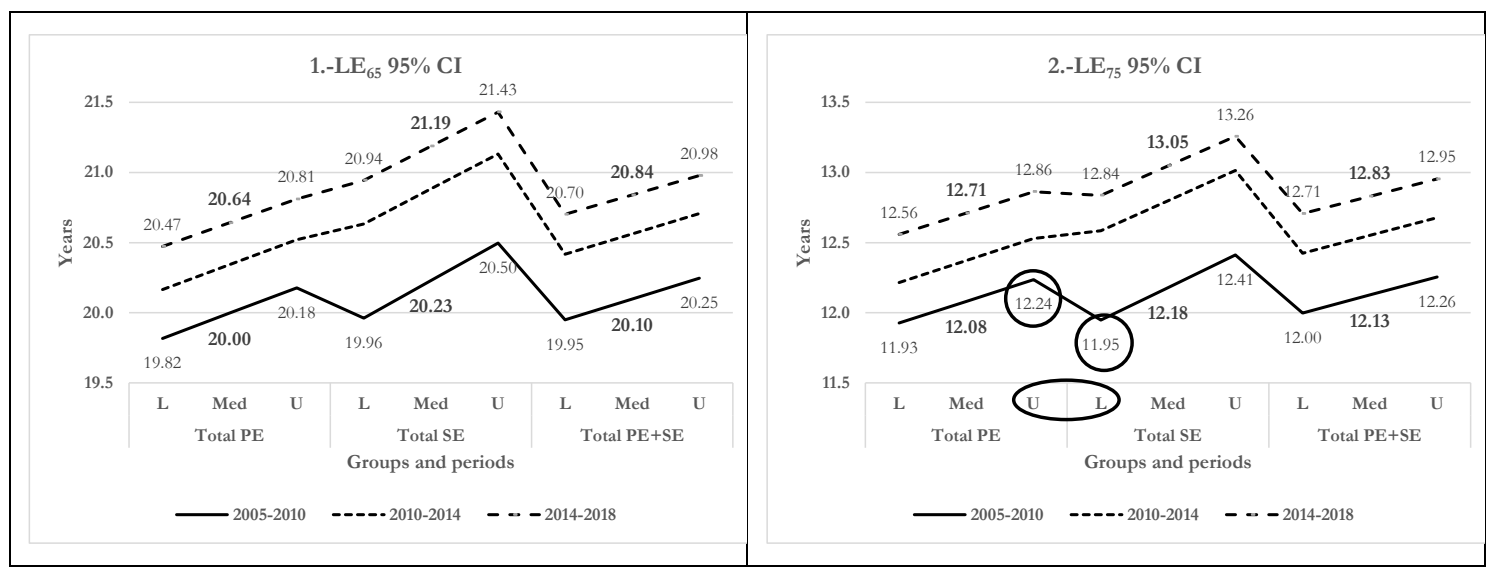

Figure 2: $\mathrm{LE}_{65}$ and $\mathrm{LE}_{75} .95 \%$ Confidence intervals

But, are these (small) LE differences between SE and PE male retirement pensioners statistically significant or not? Table 4 informs about this issue.

For all three periods analyzed, this table shows the differences in $\mathrm{LE}_{65}$ and $\mathrm{LE}_{75}\left(\mathrm{DLE}_{65}\right.$ and $\mathrm{DLE}_{75}$, respectively) between pension regime groups of pensioners, together with the standard error for those differences. The z-score value of the test statistic is used to test the null hypothesis that the difference in life expectancy is zero against the alternative of it being positive. The results show that for $\mathrm{DLE}_{65}$ are statistically significant at $1 \%$ for periods 2 and 3 and significant at $10 \%$ for the first period. For $\mathrm{DLE}_{75}$ are not significant for the first period and significant at $1 \%$ for periods 2 and 3 . The reason of the lack of statistical significance for $\mathrm{DLE}_{75}$ in $\mathrm{P}_{1}$ can be seen intuitively in Graph 2; the upper bound of $95 \%$ CI for the PE pensioners group is higher (12.24 years) than the lower bound of 95\% CI for SE group of pensioners (11.95 years).

\begin{tabular}{|c|c|c|c|}
\hline \multirow{2}{*}{ Items } & \multicolumn{3}{|c|}{ Dif. between SE and PE } \\
\hline & $\mathbf{P}_{1}$ & $\mathbf{P}_{2}$ & $\mathbf{P}_{3}$ \\
\hline $\mathrm{DLE}_{65}$ & 0.232 & 0.539 & 0.546 \\
\hline $\operatorname{Se}\left(\mathrm{DLE}_{65}\right)$ & 0.164 & 0.156 & 0.151 \\
\hline z score & $1.41^{*}$ & $3.45^{* * *}$ & $3.61^{* * *}$ \\
\hline $\mathrm{DLE}_{75}$ & 0.098 & 0.427 & 0.337 \\
\hline $\operatorname{Se}\left(\mathrm{DLE}_{75}\right)$ & 0.142 & 0.136 & 0.132 \\
\hline z score & 0.69 & $3.15^{* * *}$ & $2.54^{* * *}$ \\
\hline \multicolumn{4}{|c|}{$\begin{array}{l}* * * \text { significant at } 1 \% \text { one-tailed test. } * * \text { significant at } 5 \% \text { one-tailed test. } * \text { significant at } 10 \% \text { on } \\
\text { tailed test. }\end{array}$} \\
\hline \multicolumn{4}{|c|}{ Source: Own work } \\
\hline
\end{tabular}

And what about with the statistical significance of absolute differences in LE within pension regime groups by periods? Table 5 shows that for PE beneficiaries differences in life 
expectancy are statistically significant at $1 \%$ for both periods $\left(\mathrm{P}_{2}-\mathrm{P}_{1} ; \mathrm{P}_{3}-\mathrm{P}_{2}\right)$ and ages $(65$ and 75). The same can be said for the whole group of pensioners (PE+SE).

\begin{tabular}{|c|c|c|c|c|c|c|}
\hline \multirow{2}{*}{ Items } & \multicolumn{2}{|c|}{ PE } & \multicolumn{2}{|c|}{ SE } & \multicolumn{2}{|c|}{$\mathrm{PE}+\mathrm{SE}$} \\
\hline & $\mathbf{P}_{2}-\mathbf{P}_{1}$ & $\mathbf{P}_{3}-\mathbf{P}_{2}$ & $\mathbf{P}_{2}-\mathbf{P}_{1}$ & $\mathbf{P}_{3}-\mathbf{P}_{2}$ & $\mathbf{P}_{2}-\mathbf{P}_{1}$ & $\mathbf{P}_{3}-\mathbf{P}_{2}$ \\
\hline $\operatorname{DLE}_{65}$ & 0.346 & 0.297 & 0.653 & 0.304 & 0.463 & 0.278 \\
\hline $\operatorname{Se}\left(\mathrm{DLE}_{65}\right)$ & 0.129 & 0.125 & 0.186 & 0.178 & 0.106 & 0.102 \\
\hline z score & $2.69^{* * *}$ & $2.38^{* * *}$ & $3.50^{* * *}$ & $1.71^{* *}$ & $4.38^{* * *}$ & $2.72^{* * *}$ \\
\hline DLE $_{75}$ & 0.291 & 0.338 & 0.619 & 0.248 & 0.425 & 0.278 \\
\hline $\mathrm{Se}\left(\mathrm{DLE}_{75}\right)$ & 0.112 & 0.111 & 0.161 & 0.153 & 0.092 & 0.090 \\
\hline z score & $2.59^{* * *}$ & $3.03^{* * *}$ & $3.84^{* * *}$ & $1.62^{*}$ & $4.60^{* * *}$ & $3.08^{* * *}$ \\
\hline
\end{tabular}

Figure 3 shows complete life expectancy at ages $65, \mathrm{LE}_{65} ; 75, \mathrm{LE}_{75}$, and measured by PI level and their improvement along the periods analyzed. This figure is broken down into 4 graphs.

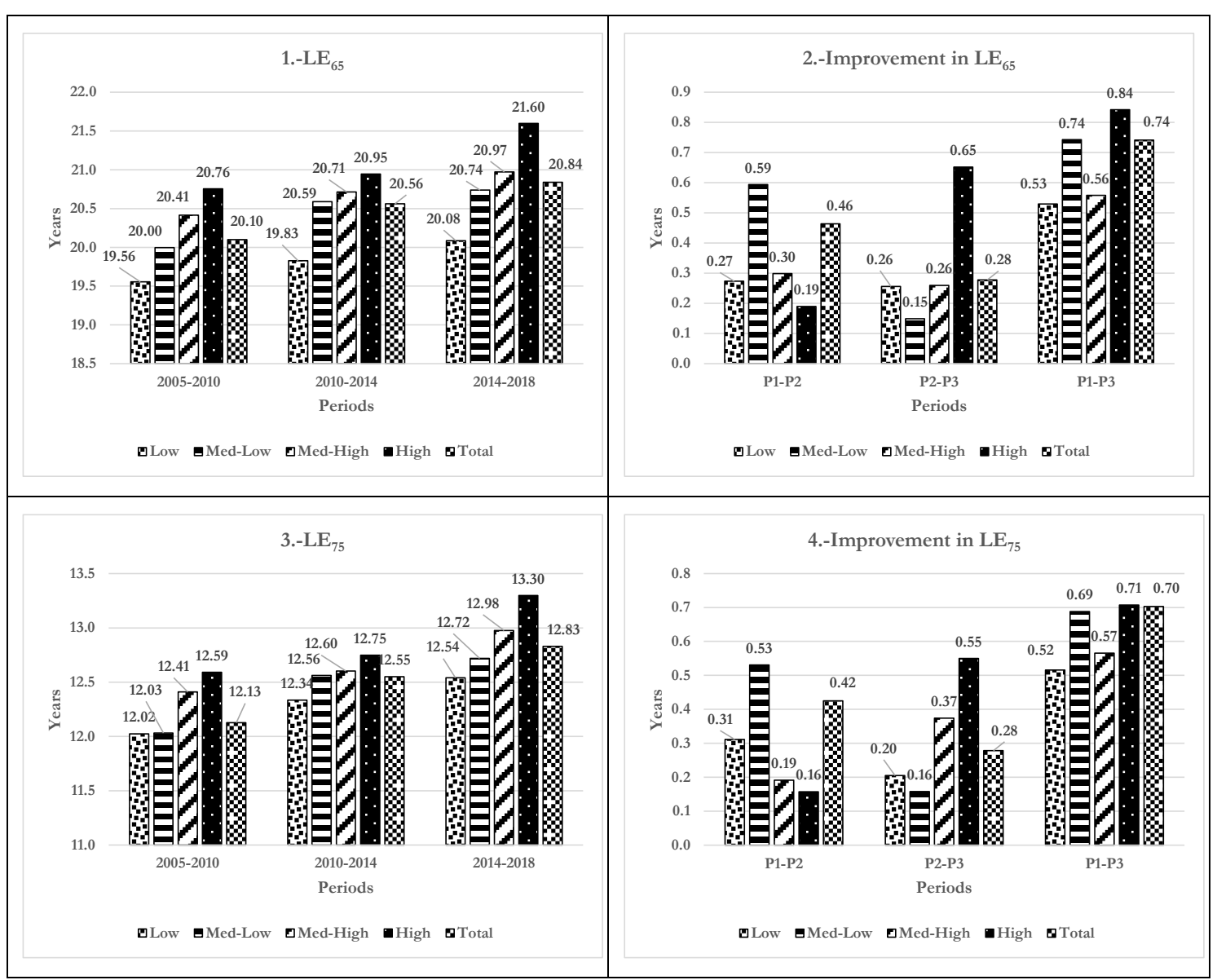

Figure 3: $\mathrm{LE}_{65}$ and $\mathrm{LE}_{75}$ and improvement in it measured by PI level (PE+SE)

Graph 1 in Figure 3 shows that $\mathrm{LE}_{65}$ has a positive link with PI level. The higher the PI level, the higher the life expectancy at age 65. Graph 2 shows that across all SEC groups (total), $\mathrm{LE}_{65}$ increases by 0.46 years between the first and second periods and by 0.28 years between the second and third. For the same periods and age group, the longevity of the general population increased by 0.81 and 0.30 years respectively. As can be seen in Graph 2, LE 65 improvements by SEC status have not been constant over time. Surprisingly, for the first period, the absolute life expectancy gains are larger in the less advantaged group ( 0.27 years) and smaller in the most advantaged group ( 0.19 years). The Med-Low group of pensioners experienced the largest life expectancy gain (0.59). For the second period, different to has 
been observed for the first period, beneficiaries in the most advantaged group show the largest $\mathrm{LE}_{65}$ gains ( 0.65 years) and Med-Low group of pensioners the smallest ( 0.15 years) For the whole period (P1-P3), in general terms can be said that the higher the PI level, the greater the improvement in life expectancy; the exception being the Med-Low group of pensioners.

But what about $\mathrm{LE}_{75}$ ? Graph 3 shows complete life expectancy at age 75, $\mathrm{LE}_{75}$, by PI levels and Graph 4 their improvement along the three periods under study. For $\mathrm{LE}_{75}$ we also see a positive link with PI level. Similar comments to those on the $\mathrm{LE}_{65}$ graphs can be made about $\mathrm{LE}_{75}$.

Figure 4 displays life expectancy and 65 and 75 years and its absolute differences by PI levels for the periods studied. This figure is broken down into 4 graphs: Graphs 1 and 3 show the difference in years for $\mathrm{LE}_{65}$ and $\mathrm{LE}_{75}$ respectively between each group and the total life expectancy while graphs 2 and 4 show the difference in years for $\mathrm{LE}_{65}$ and $\mathrm{LE}_{75}$ respectively using the highest PI group as a benchmark.

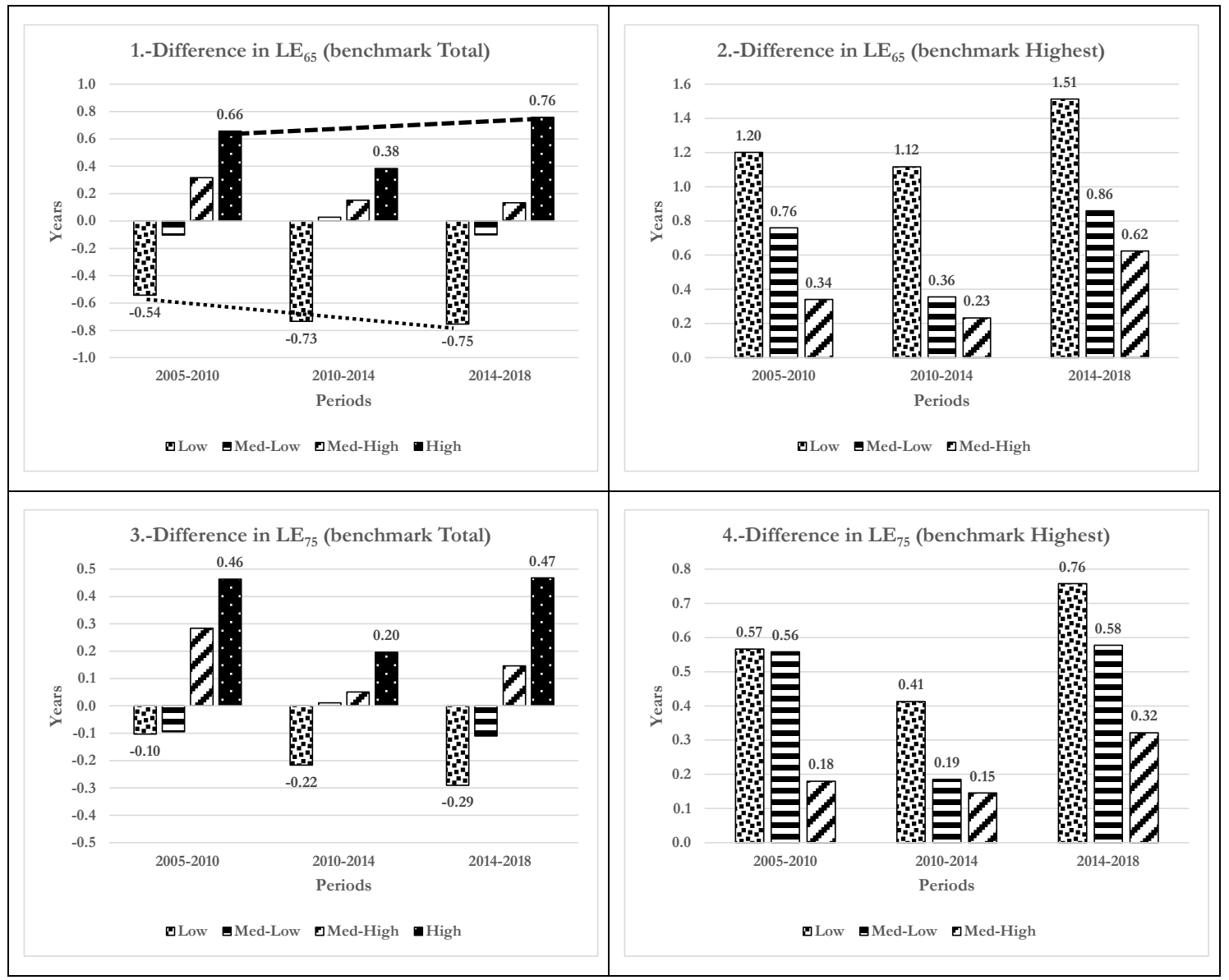

Figure 4: $\mathrm{LE}_{65}$ and $\mathrm{LE}_{75}$ and differences in it by PI levels (PE+SE)

The results are noticeable: Absolute differences in $\mathrm{LE}_{65}$ between the highest and lowest groups are found to have widened over time. For both groups in the third period, $\mathrm{LE}_{65}$ difference is further from that of the population as a whole than in the first period (Graph 1). Graph 2 provides valuable information: For 2005-2010, a gap of 1.20 years between pensioners in the lowest and the highest income groups is reported. This gap widens over time and reaches 1.51 years in 2014-2018. A similar trend can be observed if the highest PI group is compared with the other two groups. As can be seen in Graph 3 and 4 absolute differences in $\mathrm{LE}_{75}$ between the highest and lowest groups have also widened over time, but these disparities in $\mathrm{LE}_{75}$ have not been constant over time. 
The whole group of retirement beneficiaries is comprised by two subgroups: SE and PE. It is worth analyzing LE for each of them by PI level. Figure 5 shows LE at 65 and 75 years by PI levels for both collectives. This figure is broken down into 4 graphs: Graphs 1 and 3 show $\mathrm{LE}_{65}$ and $\mathrm{LE}_{75}$ respectively for SE pensioners while Graphs 2 and 4 show $\mathrm{LE}_{65}$ and $\mathrm{LE}_{75}$ for PE pensioners.

As anticipated in Table 2, SE pensioners can be considered only in two PI levels: Low and Med-Low. Med-High and High PI groups data include very few individuals, so data is unreliable. This is not surprising given that the average retirement benefit for all the pensions in payment was around $€ 10,196$ per year in 2018 for the SE regime. The same figure for PE regime was $€ 17,291$ per year in 2018 ; the average benefit was $70 \%$ higher in the PE regimen than in the SE regime. It is worth remembering that in the self-employed special regime, the contribution base is chosen annually by the worker between the minimum and maximum bases in force each year. Most of self-employed workers have decided to contribute by the minimum base in force in the 2008-2017 interval. Similar behavior is observed in previous periods. This is the main reason why the retirement benefits are lower than in the PE regime.

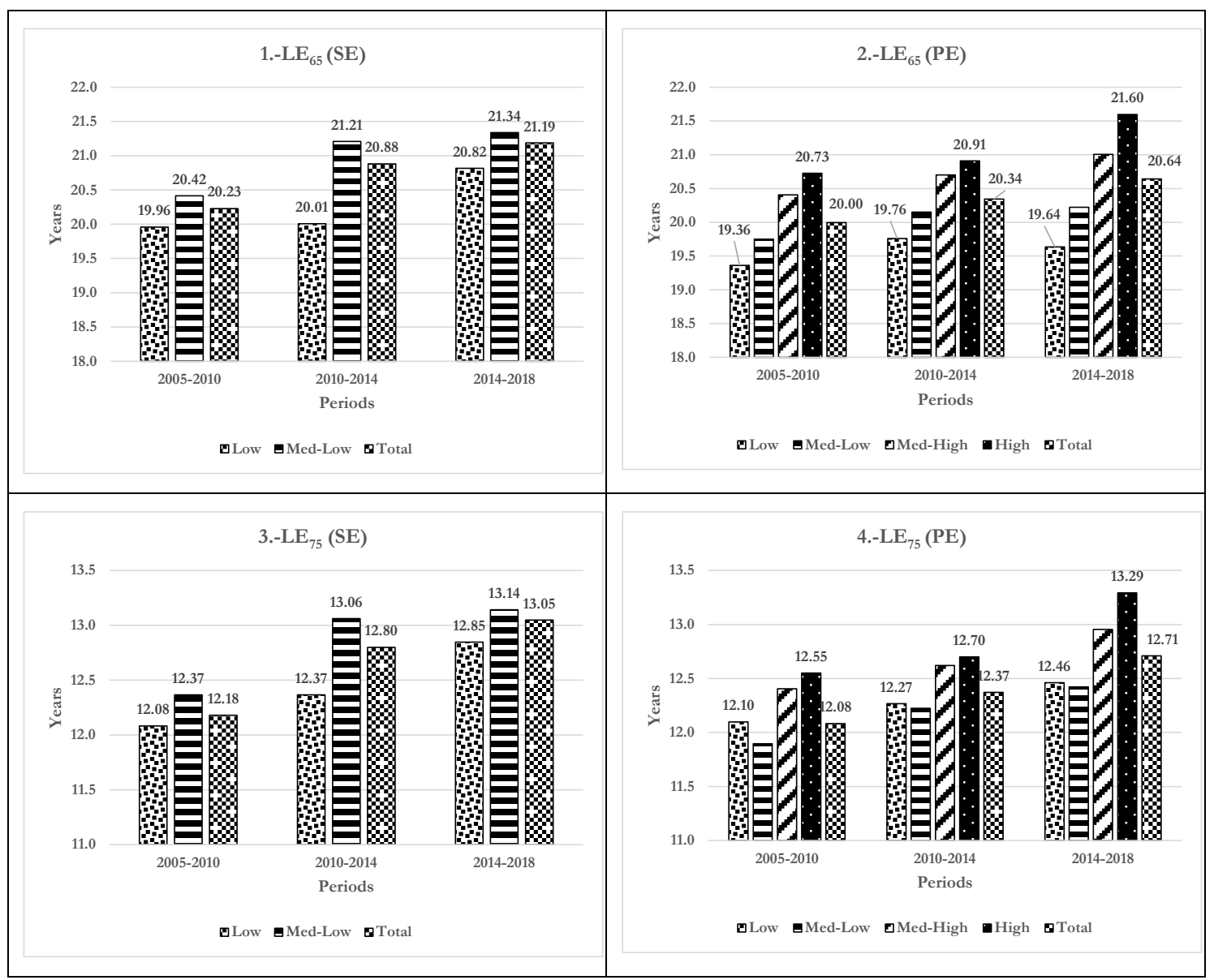

Figure 5: $\mathrm{LE}_{65}$ and $\mathrm{LE}_{75}$ by PI level for both regimes.

For both groups of pensioners: PE and SE, Table 6 shows information about the level of statistical significance of the absolute differences in LE between PI groups by periods and ages by comparing the DLE between the highest and the lowest group in each of them.

For PE beneficiaries DLE $_{65}$ are statistically significant at $1 \%$ for all periods whereas for $D_{2 L}$ are significant at $1 \%$ for $\mathrm{P}_{3}$ and at $10 \%$ for periods $\mathrm{P}_{1}$ and $\mathrm{P}_{2}$. DLE for SE beneficiaries are less statistically significant given that the reduced difference in the amount of benefit between the Med-Low and PI groups. In any case, for the second period DLE 65 
and $\mathrm{DLE}_{75}$ are found to be statistically significant at $1 \%$ level. In periods one and three, DLE $_{65}$ are statistically significant at $10 \%$ for all periods whereas for DLE $_{75}$ the null hypothesis cannot be rejected.

\begin{tabular}{|c|c|c|c|c|c|c|}
\hline \multirow[t]{2}{*}{ Items } & \multicolumn{3}{|c|}{$\begin{array}{l}\text { Between High and low PI } \\
\text { groups } \\
\text { (PE) }\end{array}$} & \multicolumn{3}{|c|}{$\begin{array}{c}\text { Between Med-Low and low PI } \\
\text { groups } \\
\text { (SE) }\end{array}$} \\
\hline & $\mathbf{P}_{1}$ & $\mathbf{P}_{2}$ & $\mathbf{P}_{3}$ & $\mathbf{P}_{1}$ & $\mathbf{P}_{2}$ & $\mathbf{P}_{3}$ \\
\hline $\mathrm{DLE}_{65}$ & 1.367 & 1.150 & 1.960 & 0.459 & 1.202 & 0.520 \\
\hline $\operatorname{Se}\left(\mathrm{DLE}_{65}\right)$ & 0.347 & 0.344 & 0.330 & 0.335 & 0.337 & 0.324 \\
\hline z score & $3.94^{* * *}$ & $3.34^{* * *}$ & $5.95^{* * *}$ & $1.37^{*}$ & $3.57^{* * *}$ & $1.61^{*}$ \\
\hline $\operatorname{DLE}_{75}$ & 0.452 & 0.433 & 0.830 & 0.284 & 0.694 & 0.295 \\
\hline Se(DLE $\left.{ }_{75}\right)$ & 0.306 & 0.309 & 0.301 & 0.253 & 0.260 & 0.275 \\
\hline z score & $1.48^{*}$ & $1.40^{*}$ & $2.76^{* * *}$ & 1.12 & $2.67^{* * *}$ & 1.07 \\
\hline
\end{tabular}

An intuitive method to better understand the statistical significance of absolute differences in life expectancy between pension income groups is to build confidence intervals for life expectancy using bootstrap, as described in Appendix 1. Figure 6 illustrates the sample distributions of $\mathrm{LE}_{65}$ in $\mathrm{P}_{1}$ for some pension income groups of PE (Graph 1) and SE (Graph 2) beneficiaries. The probability distributions of $\mathrm{LE}_{65}$ are computed using 1,000 simulations that capture the uncertainty in the survival process of these pension income groups.

For PE beneficiaries, the simulated $\mathrm{LE}_{65} 95 \%$ confidence intervals are (18.90-19.92) and (20.27-21.21) respectively for the low and high pension income groups. The DLE 65 for the mean values is 1.37 years (20.74-19.37). For SE beneficiaries the simulated $\mathrm{LE}_{65} 95 \%$ confidence intervals are (19.37-20.52) and (20.11-20.76) respectively for the low and medium-low pension income groups. The $\mathrm{DLE}_{65}$ for the mean values is 0.46 years (19.9820.43).

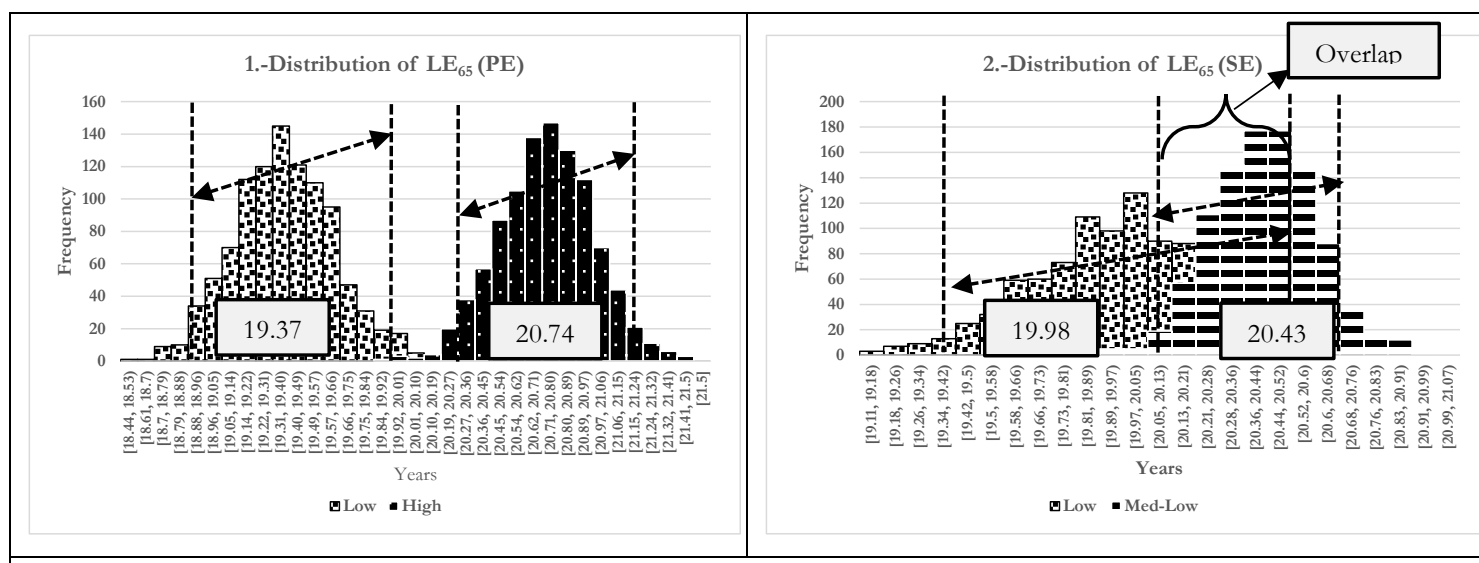

Figure 6: Histograms of the simulated $\mathrm{LE}_{65}$ in $\mathrm{P}_{1}$ for some $\mathrm{PE}$ and $\mathrm{SE}$ pension income groups.

Figure 6 illustrates the results shown in Table A6 Appendix 1 (which is equivalent to Table 6 in this section). Graph 1 shows that the $\mathrm{DLE}_{65}$ for PE beneficiaries is statistically significant at $1 \%$, given that the $95 \%$ confidence intervals are not overlapping. Graph 2 shows that the two distributions are quite different, but the $95 \%$ confidence intervals are partly overlapping, indicating that the statistical significance is attained at the higher level.

Table 7 gives information about the level of statistical significance of the absolute differences in life expectancy between pension regime groups by equivalent pension income groups and periods. Differences in life expectancy between medium-low groups are significant at $1 \%$ for 
ages 65 and 75. However, the differences in life expectancy between low groups are not significant for age 75 and only at $1 \%$ for $\mathrm{P}_{3}$ and $10 \%$ for $\mathrm{P}_{1}$ at age 65 .

\begin{tabular}{|c|c|c|c|c|c|c|}
\hline \multirow{3}{*}{ Items } & equiva & pensio & ome gr & and per & & \\
\hline & \multicolumn{3}{|c|}{$\begin{array}{l}\text { Between low groups } \\
\text { (SE-PE) }\end{array}$} & \multicolumn{3}{|c|}{$\begin{array}{c}\text { Between medium-low groups } \\
\text { (SE-PE) }\end{array}$} \\
\hline & $\mathbf{P}_{1}$ & $\mathbf{P}_{2}$ & $\mathbf{P}_{3}$ & $\mathbf{P}_{1}$ & $\mathbf{P}_{2}$ & $\mathbf{P}_{3}$ \\
\hline $\operatorname{DLE}_{65}$ & 0.597 & 0.246 & 1.180 & 0.665 & 1.057 & 1.113 \\
\hline $\operatorname{Se}\left(\operatorname{DLE}_{65}\right)$ & 0.382 & 0.398 & 0.393 & 0.216 & 0.196 & 0.190 \\
\hline z score & $1.56^{*}$ & 0.62 & $3.00^{* * *}$ & $3.08^{* * *}$ & $5.38^{* * *}$ & $5.87^{* * *}$ \\
\hline DLE $_{75}$ & -0.017 & 0.099 & 0.385 & 0.470 & 0.837 & 0.720 \\
\hline $\operatorname{Se}\left(\mathrm{DLE}_{75}\right)$ & 0.282 & 0.308 & 0.335 & 0.193 & 0.172 & 0.163 \\
\hline z score & -0.06 & 0.32 & 1.15 & $2.44^{* * *}$ & $4.86^{* * *}$ & $4.41^{* * *}$ \\
\hline \multicolumn{7}{|c|}{ Source: Own work } \\
\hline
\end{tabular}

Figure 7 presents the histograms of the simulated $\mathrm{LE}_{65}$ for equivalent low groups in $\mathrm{P}_{1}$ (Graph 1) and $\mathrm{P}_{3}$ (Graph 2). These are a useful graphic tool to better understand the results shown in Table A8 Appendix 1 (which is equivalent to Table 7 in this section).

Graph 1 shows that some of the $95 \%$ confidence intervals for $\mathrm{LE}_{65}$ are overlapping given that the values are (18.90-19.92) and (19.37-20.52) respectively for PE and SE. This is why the level of statistical significance for $\mathrm{DLE}_{65}$ is at $10 \%$ in the one-tailed test in $\mathrm{P}_{1}$. Conversely, Graph 2 clearly shows that there is no overlap between the $95 \%$ confidence intervals for the simulated $\mathrm{LE}_{65}$ for equivalent low-income groups in $\mathrm{P}_{3}$. The simulated $\mathrm{LE}_{65} 95 \%$ confidence intervals are (19.11-20.15) and (20.28-21.38) respectively for PE and SE beneficiaries and the $\mathrm{DLE}_{65}$ for the mean values is 1.19 years $(20.82-19.63)$. This is why the DLE 65 is statistically significant at $1 \%$ in the third period.

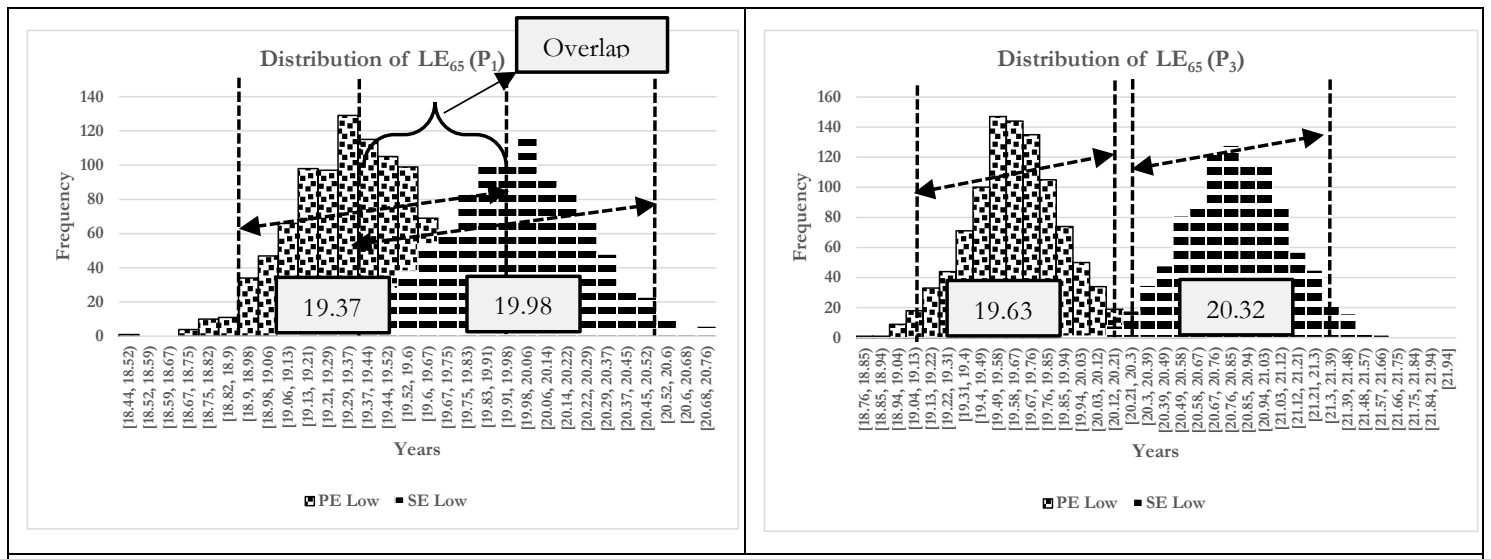

Figure 7: Histograms of the simulated $\mathrm{LE}_{65}$ for equivalent low-income groups in $\mathbf{P}_{1}$ and $\mathbf{P}_{3}$.

What about relative inequalities in life expectancy between pension income groups? Figure 8 presents this information broken down into 4 graphs. Graphs 1 and 2 show the relative difference $(\mathrm{RD})$ in $\mathrm{LE}_{65}\left(\mathrm{RDLE}_{65}\right)$ between a given pension income group and the wealthiest, for total pensioners (SE and PE) and PE retirement beneficiaries respectively. This is calculated as the ratio between life expectancy in the highest pension income group and that in the low, medium-low or medium-high group minus 1, expressed as a percentage. Graphs 3 and 4 are the equivalents to Graphs 1 and 2 respectively for $L_{75}$. 


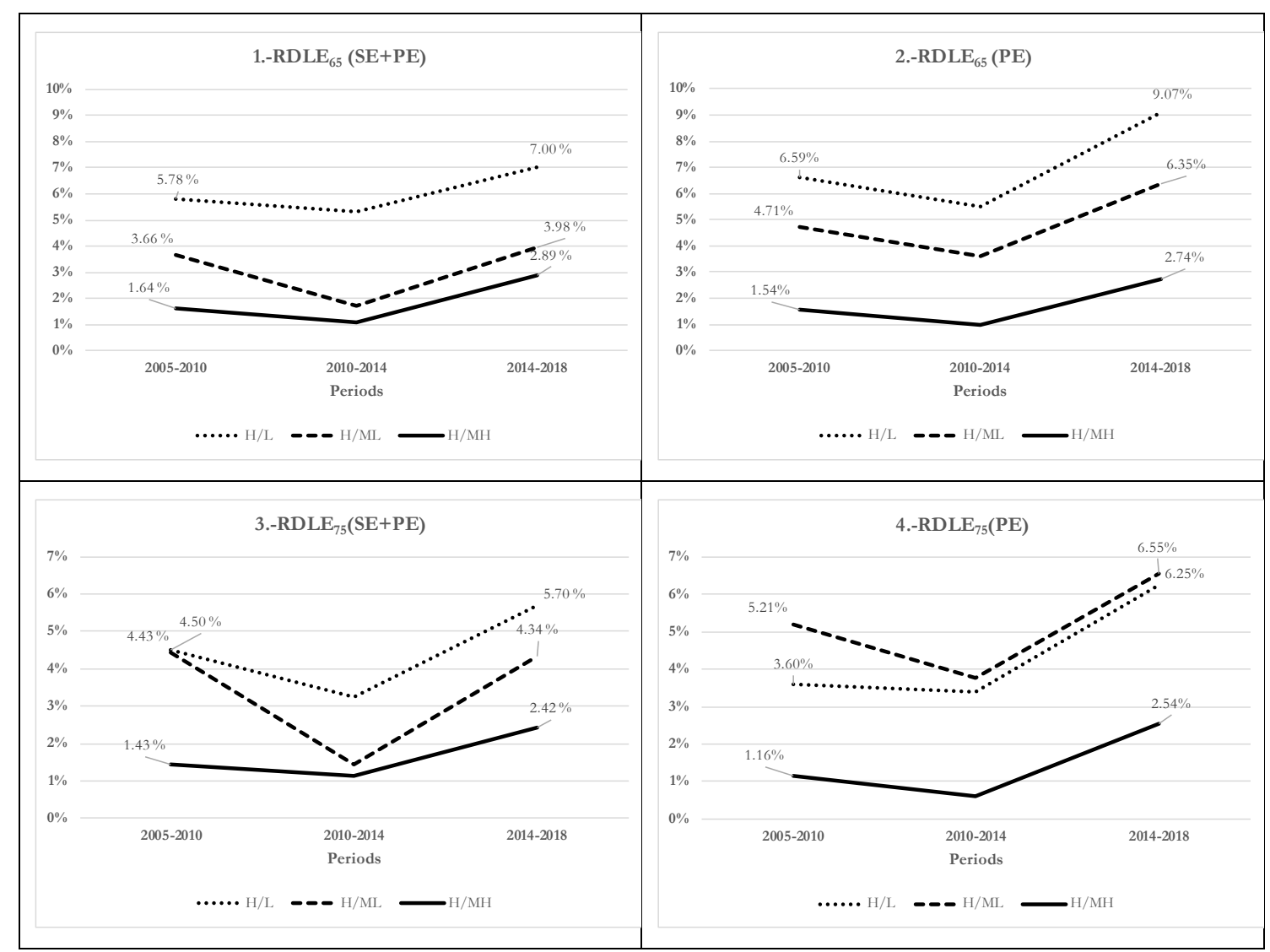

Figure 8: Relative differences (RD) in $\mathrm{LE}_{65}$ and $\mathrm{LE}_{75}$.

There is no doubt that relative inequality between pension income groups has grown over time as regards life expectancies for the whole group of pensioners (SE+PE) and for PE beneficiaries. For 2005-2010, if we consider the whole group of pensioners (Graph 1), we estimate that $\mathrm{LE}_{65}$ for the most disadvantaged group is $5.78 \%$ lower than for the most advantaged. In the case of PE beneficiaries and for the same period, the RDLE 65 reaches $6.59 \%$. Two periods later, in 2014-2018, the inequality is even greater, with $\mathrm{LE}_{65}$ being $7 \%$ $(9.07 \%)$ lower than the benchmark group for the whole (PE) group of pensioners. Similar figures can be observed in the case of $\mathrm{LE}_{75}$ (Graphs 3 and 4). The same pattern can be seen for all the other pension income groups. For retirement pension beneficiaries as a whole, a low relative difference of 1.64\% $\left(\mathrm{LE}_{65}\right)$ and $1.43 \%\left(\mathrm{LE}_{75}\right)$ is shown for the medium-high group in the first period. In the second period this difference is lower, but in the third it increases again from $1.11 \%$ to $2.89 \%$ and from $1.14 \%$ to $2.42 \%$ respectively.

To conclude this section, we present a comparison between our results for the whole retirement pensioner group (SE+PE) and the life expectancy of the Spanish population as a whole (Figure 9, Graph 1 for $\mathrm{LE}_{65}$ and Graph 2 for $\mathrm{LE}_{75}$ ).

As expected, individuals in the sample live longer than the general population because one of the requirements for obtaining a retirement pension is to have contributed for at least 15 (currently 20) years, including at least 2 of the last 15 (20) years. This requirement is likely to exclude some of the most at-risk members of the Spanish population because of the strong correlation between labour force participation and health observed in various countries (Waldron, 2007; Urbanaviciute et al., 2019; Piłat et al., 2020). As mentioned earlier, disabled beneficiary and early retiree collectives with lower life expectancies than the general population were excluded from our sample. 
Absolute differences in life expectancy are seen to narrow over time. For 2005-2010, a gap in life expectancy of 1.92 years between $\mathrm{SE}+\mathrm{PE}$ and the Spanish population is reported. This gap is widest in the most advantaged group (2.58 years) and narrowest in the least advantaged (1.38). For the second period, the gap is smaller than for the first for all pension income groups and the whole population of retirement beneficiaries. The gap narrows from 1.92 years to 1.57 years. For the third period we see a further reduction in absolute differences in life expectancy for all pension income groups except for that with the highest pensions. The difference in $\mathrm{LE}_{65}$ between $\mathrm{SE}+\mathrm{PE}$ and the Spanish population is 1.55 years (a slight reduction of 0.02 years), whereas for the most advantaged group the reported gap widens to 2.30 years, 0.35 years more than in the previous period.

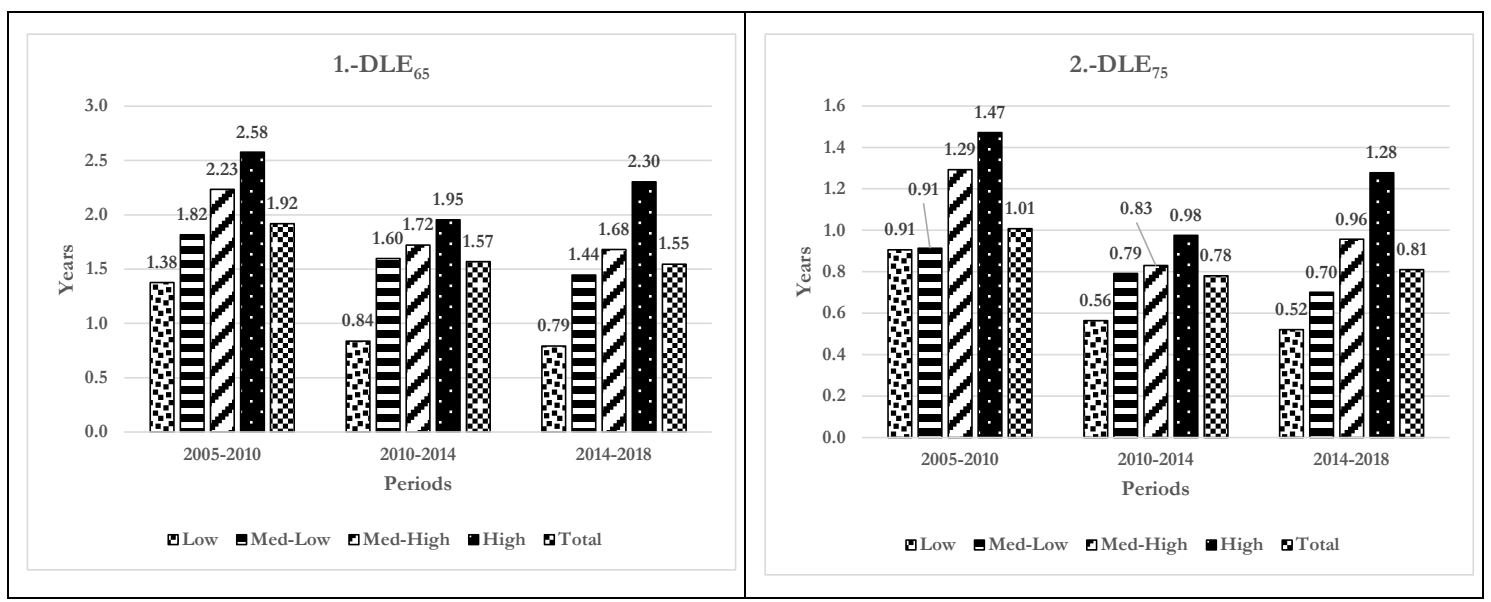

Figure 9: $\mathrm{DLE}_{65}$ and $\mathrm{DLE}_{75}$ by pension income level (Spanish population as a benchmark)

A very similar pattern can be seen in Graph 2 for differences in $\mathrm{LE}_{75}$. Naturally the differences are smaller than for age of 65 , but they are certainly not negligible. Absolute differences in life expectancy are seen to narrow over time, from 1.01 years for the first period to 0.81 years in the third. The most advantaged group continues with an absolute difference in $\mathrm{LE}_{75}$ of 1.28 years, whereas for the least advantaged group this is only 0.52 years.

\section{4.-Discussion}

Contrary to what has been observed in countries such as Italy, Finland and Japan, although similar to the case of Germany, we find that $\mathrm{LE}_{65}$ is slightly higher for SE than for PE retirement pensioners. We also find a positive association between pension income levels and life expectancy for the male retirement pensioner group as a whole. The trends for the full period analysed show that the gaps between life expectancy by pension income level have widened.

Our findings are in line with those of Regidor et al., (2012), Kulhánová et al. (2014), Mackenbach et al. (2017), and Solé-Auró et al. (2020). The paper by Regidor et al. (2012) concludes that mortality inequalities between older Spanish adults are small. The ubiquity of social safety nets and widespread adherence to the Mediterranean diet may be responsible for this finding. For Kulhánová et al. (2014) these smaller inequalities in mortality seem to be a historical coincidence rather than the outcome of deliberate policies. The paper by Mackenbach et al. (2017) also reports that relative inequalities in mortality are largest in Eastern Europe (Czech Republic, Lithuania, Hungary, Estonia and Slovenia) and smallest in the South (Spain and Italy). Solé-Auró et al. (2020) suggest that this lower gradient in mortality might be partly explained by a later process of economic modernization or by the existence of health assets that have traditionally received less attention in these countries. 
These health assets, such as greater family network density and less inequality of access to healthy food, may be critical elements of political action. None of the above-mentioned papers use pension income levels as a socioeconomic indicator to evaluate life expectancy.

A plausible explanation for the contradictory association between $\mathrm{LE}_{65}$ and pension regime in Spain could involve the existence of unobserved earnings. In general terms, SE beneficiaries have a higher life expectancy than PE pensioners despite the average retirement benefit being (much) lower for SE than for PE pensioners. The estimated associations would be biased if SE pensioners actually had additional sources of income that we did not see, i.e. what have been termed "unobserved earnings" in the literature. With this term we refer to all unmeasured earnings that may actually affect the pensioner's position in a particular pension income level group.

Von Gaudecker and Scholz (2007) and Shkolnikov et al. (2007) attribute their evidence of a counterintuitive J-shaped relationship between life expectancy at age 65 and lifetime earnings in Germany to unobserved earnings.

\begin{tabular}{|c|c|c|c|c|c|c|}
\hline \multicolumn{7}{|c|}{$\begin{array}{l}\text { Table 8: } \mathrm{LE}_{65} \text { and the average benefit in euros for each pension income group } \\
\text { broken down by pension regime }\end{array}$} \\
\hline $\begin{array}{l}\text { Pension } \\
\text { Regime }\end{array}$ & \multicolumn{2}{|c|}{ PE } & \multicolumn{4}{|c|}{ SE } \\
\hline \multicolumn{7}{|c|}{$2005-2010$} \\
\hline Items & $\mathbf{L E}_{65}$ & $\begin{array}{l}\text { Average } \\
\text { Benefit }\end{array}$ & $\mathbf{L E}_{65}$ & $\begin{array}{l}\text { Average } \\
\text { Benefit }\end{array}$ & $\begin{array}{c}\text { Equivalent } \\
\text { Average } \\
\text { Benefit }\end{array}$ & $\mathrm{EAB} / \mathrm{AB}$ \\
\hline Low & 19.36 & $3,486.90$ & 19.96 & $4,275.29$ & $14,281.57$ & 3.34 \\
\hline Med-Low & 19.75 & $10,550.76$ & 20.42 & $9,859.92$ & $22,575.93$ & 2.29 \\
\hline Med-High & 20.41 & $22,416.19$ & n.a. & n.a. & n.a. & n.a. \\
\hline High & 20.73 & $28,202.24$ & n.a. & n.a. & n.a. & n.a. \\
\hline Total & 20 & $15,047.00$ & 20.23 & $6,627.16$ & $19,206.09$ & 2.90 \\
\hline \multicolumn{7}{|c|}{ 2014-2018 } \\
\hline Low & 19.64 & $4,795.15$ & 20.82 & $5,595.17$ & $21,951.00$ & 3.92 \\
\hline Med-Low & 20.22 & $13,338.84$ & 21.34 & $12,446.29$ & $29,515.46$ & 2.37 \\
\hline Med-High & 21.01 & $24,691.91$ & n.a. & n.a. & n.a. & n.a. \\
\hline High & 21.60 & $33,283.73$ & n.a. & n.a. & n.a. & n.a. \\
\hline Total & 20.64 & $19,384.68$ & 21.19 & $9,121.68$ & $27,380.03$ & 3.00 \\
\hline
\end{tabular}

Table 8 gives information about $\mathrm{LE}_{65}$ and the average benefit for each pension income group broken down by pension regime for the first and third periods analysed.

For the period 2005-2010 the average benefit for SE beneficiaries is only $44 \%$ of the average benefit of $\mathrm{PE}$ beneficiaries, whereas $\mathrm{LE}_{65}$ is 0.23 years higher and this difference is statistically significant, as shown in the previous section. Similarly, for the third period the average pension income of SE pensioners is around $47 \%$ that of $\mathrm{PE}$ recipients and $\mathrm{LE}_{65}$ is 0.55 years higher. Is anything wrong with this evidence? As mentioned before, we suspect that there might be additional sources of income involved that are not included in the single socioeconomic indicator for SE beneficiaries.

Under the assumption that the real association between $\mathrm{LE}_{65}$ and pension income is that observed for PE beneficiaries, it is easy to find a linear relationship between life expectancy and the amount of benefit. The Equivalent Average Benefit column for SE beneficiaries shows the equivalent benefit consistent with the observed life expectancy. 
In the first period, 2005-2010, for the low pension income level the "official" average benefit was 4,275.29 euros/year, whereas the estimated average benefit according to their $\mathrm{LE}_{65}$ should be 14,281.57 euros/year, i.e. 3.34 times higher than the observed value. For the period 2014-2018 the estimated average benefit would be even higher, 3.92 times the observed benefit for the lowest pension income group.

If we look at the medium-low group of retirement pensioners, the estimated average benefit in line with their $\mathrm{LE}_{65}$ would be 2.29 times higher than the observed value for the first period and 2.37 times higher for 2014-2018. In short, there is a misclassification if we only consider the observed SE pension benefit. In the first period the group classified as SE medium-low would be equivalent to the PE medium-high group, while in the third period this group would be between the PE medium-high and high groups

What could these suspected additional sources of income be?

1.-Income from active retirement. From 2013 to 2018 the number of SE beneficiaries in this state of "active retirement" multiplied by 6. If SE beneficiaries meet certain legal requirements, working is compatible with the receiving $50 \%$ of the pension. Since November 2017, if the SE beneficiary has at least one employee, the amount of pension compatible with working is $100 \%$ of their retirement benefit ${ }^{10}$.

2.-Receipt of income or capital from individual supplementary social security systems that were contracted during their working life, given that the contribution base in this special scheme is chosen annually by the worker between the minimum and maximum bases in force each year.

3.-Receipt of income from accumulated capital linked to their business assets during working life: income from business transfers upon retirement, dividend income from shares in the businesses in which they worked as managers/administrators (corporate self-employed) as long as they only own their share and do not continue to work, and/or income from the rental/leasing of real estate (urban or rustic) in connection with their former business as a self-employed person.

To summarize, all the unmeasured earnings that could affect a pensioner's position in a particular pension income level group could explain why SE beneficiaries have higher life expectancy than PE pensioners despite the fact that their average retirement benefit is (much) lower. Either way, this issue clearly goes beyond the scope of this paper and further research would need to be done to unravel this apparent puzzle.

\section{5.-Conclusions}

Taking stock of the situation in the awareness that using the initial pension income level as the sole indicator of the socioeconomic status of the retired population has its limitations, it can be said that the paper's objective has been fully achieved, given that the four basic research questions were answered. We have found differences in life expectancy between SE and PE groups of retirement pensioners and between pension income groups. The differences are small but statistically significant. The trends for the entire period analysed show that the difference in life expectancy as measured by pension regime and pension income level has widened further.

Contrary to what has been observed in certain other countries, $\mathrm{LE}_{65}$ is slightly higher for selfemployed than for paid employee retirement pensioners. For 2005-2010, a gap in life expectancy of 0.23 years between SE and PE retirement pensioners is reported. This gap

10 http://www.seg-social.es/wps/wcm/connect/wss/3aa925cb-ece2-4477-acbf-7e3f853d8977/TOMO+III.+ INFORME+ECONOMICO-FINANCIERO-P.pde?MOD=AJPERES\&CVID= 
widens to 0.55 years in 2014-2018. A similar trend can be observed when the pension income group is considered. For 2005-2010 the gap in $\mathrm{LE}_{65}$ between pensioners in the lowest and highest income groups is 1.20 years. This widens over time to reach 1.51 years in 2014-2018. However, although these inequalities are relatively small, they are statistically significant.

We have briefly discussed an explanation for the contradictory association between $\mathrm{LE}_{65}$ and pension regime in Spain, i.e. unobserved earnings. All the unmeasured earnings that may affect a pensioner's position in a particular pension income level group could explain why SE beneficiaries have higher life expectancy than PE pensioners, despite the fact that their average retirement benefit is (much) lower. Further research needs to be done in this area.

The social security policy implications emerging from our research are evident. Life expectancy gaps by socioeconomic status and pension regime should be taken into account for a variety of issues involving social security schemes, e.g. to establish the age of eligibility for retirement pensions and early access to benefits, to compute the annuity factors used to determine initial retirement benefits, and to value the system's liabilities for retirement pensioners.

\section{6.-References}

Belloni, M., Alessie, R., Kalwij, A. and Marinacci, C. (2013). Lifetime income and old age mortality risk in Italy over two decades, Demographic Research 29, 1261-1298.

Bosley, T.; M. Morris and K. Glenn (2018). Mortality by Career-Average Earnings Level. Actuarial study, 124. Social Security Administration, Office of the Chief Actuary. https://www.ssa.gov/OACT/NOTES/pdf studies/study124.pdf

Camarda, C. G. (2012). MortalitySmooth: An R Package for Smoothing Poisson Counts with P-Splines. Journal of Statistical Software. 50, 1-24. http://www.jstatsoft.org/v50/i01/.

Chiang, C.L. (1984). The Life Table and its Applications, Malabar, FL: Robert E. Krieger Publishers.

Kalwij, A., Alessie, R., and Knoef, M. (2013). The association between individual income and remaining life expectancy at the age of 65 in the Netherlands. Demography 50(1): 181-206. doi:10.1007/s13524-012-0139-3.

Kibele, E.U.B., Jasilionis, D., and Shkolnikov, V.M. (2013). Widening socioeconomic differences in mortality among men aged 65 years and older in Germany. Journal of Epidemiology and Community Health 67(5): 453-457

Kulhánová, I., Bacigalupe, A., Eikemo, T. A., Borrell, C., Regidor, E., Esnaola, S., Mackenbach,J. P., \& Eurothine consortium (2014). Why does Spain have smaller inequalities in mortality? An exploration of potential explanations. European journal of public health, 24(3), 370-377. DOI: https://doi.org/10.1093/eurpub/cku006

Lallo, C. and Raitano, M. (2018). Life expectancy inequalities in the elderly by socioeconomic status: evidence from Italy. Population health metrics 16(1), 7.

Li, N. (2015). The probabilistic life table and its applications to Canada. Canadian Studies in Population 42(1-2), 117-129.

Longevity Science Panel (2018). Life expectancy: Is the socio-economic gap narrowing? Accessed April 16, 2020. http://www.longevitypanel.co.uk/viewpoint/life-expectancy-isthe-socio-economic-gap-narrowing 
Longevity Science Panel (2020). An analysis of mortality trends in developed countries, focusing on the recent slowdown in mortality improvements. Accessed April 16, 2020. https://www.longevitypanel.co.uk/ files/LSP2020 Report.pdf

Luy, M., Wegner-Siegmundt, C., Wiedemann, A., \& Spijker, J. (2015). Life expectancy by education, income, and occupation in Germany: estimations using the longitudinal survival method. Comparative Population Studies, 40(4), 399-436.

Mackenbach JP, Bopp M, Deboosere P., et al. (2017). Determinants of the magnitude of socioeconomic inequalities in mortality: A study of 17 European countries. Health \& Place 2017; 47: 44-53. DOI: https://doi.org/10.1016/j.healthplace.2017.07.005

Mazza A., and A. Punzo (2014). DBKGrad: An R Package for Mortality Rates Graduation by Discrete Beta Kernel Techniques. Journal of Statistical Software 57(2), 1-18.

Pensioners and annuitants working group (PAWG) (2012). Pensioners and annuitants in Italy: mortality from 1980 to 2009 and projections to 2040. Italian Actuarial Profession bodies (Consiglio dell'Ordine Nazionale degli Attuari e Consiglio Nazionale degli Attuari).

Pérez-Salamero Gonzalez, J.M., Regúlez-Castillo, M. and Vidal-Meliá, C. (2017). The continuous sample of working lives: improving its representativeness. SERIEs. Journal of the Spanish Economic Association 8, 43-95.

Piłat, A., Galaś, A., Wilga, M., Cabello, M., Koskinen, S., Haro, J. M. Tobiasz-Adamczyk, B. (2020). Gender perspective in the analysis of the relationship between health and work cessation, and how to deal with it. International Journal of Occupational Medicine and Environmental Health, 33(3), 365-384. https://doi.org/10.13075/ijomeh.1896.01351

Polvinen A, Laaksonen M, Gould R, Lahelma E, Leinonen T, Martikainen P. (2015). Socioeconomic inequalities in cause-specific mortality after disability retirement due to different diseases. Scandinavian Journal of Public Health 43:159-168.

Regidor, E. A.E. Kunst, F. Rodríguez-Artalejo, J.P. Mackenbach (2012). Small socioeconomic differences in mortality in Spanish older people European Journal of Public Health, $22,80-85$.

Scherbov, S., and D. Ediev. (2011). Significance of life table estimates for small populations: Simulation based study of standard errors. Demographic Research 24:527-50.

Shkolnikov, V.M., Scholz, R., Jdanov, D.A., Stegmann, M., and von Gaudecker, H.M. (2008). Length of life and pensions of five million retired German men. European Journal of Public Health 18(3): 264-269.

Solé-Auró, A.; Martín, U.; Domínguez Rodríguez, A. (2020). Educational Inequalities in Life and Healthy Life Expectancies among the 50-Plus in Spain. Int. J. Environ. Res. Public Health,17, 3558. DOI: https://doi.org/10.3390/ijerph17103558

Tanaka H, Miyawaki A, Toyokawa S, Kobayashi Y. (2018). Relationship of relative poverty and social relationship on mortality around retirement: a 10-year follow-up of the Komo-Ise cohort. Environmental Health and Preventive Medicine 23(1): 64

Tetzlaff, F., Epping J., Sperlich S., and J Tetzlaff. (2020). Widening income inequalities in life expectancy? Analysing time trends based on German health insurance data. Journal of Epidemiology and Community Health Apr 10. doi: 10.1136/jech-2019-212966. 
Toivanen, S., Griep, R. H., Meller, C., Vinberg, S., \& Eloranta, S. (2016). Mortality differences between self-employed and paid employees: a 5-year follow-up study of the working population in Sweden. Occupational and Environmental Medicine 73, 627-636.

Urbanaviciute, I., De Witte, H., \& Rossier J. (2019). Perceived job insecurity and self-rated health: testing reciprocal relationships in a five-wave study. Social Science Medicine, 233, 201207.

Von Gaudecker, H.M. and Scholz, R.D. (2007). Differential mortality by lifetime earnings in Germany. Demographic Research 17(4): 83-108

Waldron, H. (2007). Trends in Mortality Differentials and Life Expectancy for Male Social Security-Covered Workers, by Socioeconomic Status. Social Security Bulletin 67(3): 1-28.

Wen, J.; T. Kleinow and A. J. G. Cairns (2020). Trends in Canadian Mortality by Pension Level: Evidence from the CPP and QPP, North American Actuarial Journal, DOI: 10.1080/10920277.2019.1679190

Wenau, G.; Grigoriev, P.; and Shkolnikov, V. (2019). Socioeconomic Disparities in Life Expectancy Gains among Retired German Men, 1997-2016. Journal of Exidemiology and Community Health 73:605-611.

Wu, C., Odden, M. C., Fisher, G., \& Stawski, R. S. (2016). Association of retirement age with mortality: a population-based longitudinal study among older adults in the USA. Journal of Epidemiology and Community Health, 70(9), 917-923. 


\section{7.-Appendix 1: an alternative approach to building confidence intervals}

An alternative approach used to build life expectancy confidence intervals is based on Camarda (2012). To be specific, we modify the R routine (Life'TableFUN.R) provided by Camarda ${ }^{11}$ using bootstrap.

Following Li (2015) we use the simulated life expectancies obtained by Camarda's bootstrapping procedure in order to test whether a life-table variable, in this case life expectancy at age 65 for one pension income group, $L_{65}^{2}$, is bigger than the same variable for another pension income group, $\mathrm{LE}_{65}^{1}$ i.e. whether such a difference is statistically significant or whether it may appear purely by random chance.

We will denote by the use of $\operatorname{SLE}_{65(\mathrm{i})}^{1}$ and $\operatorname{SLE}_{65(\mathrm{i})}^{2}, i=1, \ldots, n_{s}$ the simulated life expectancy for each group at age 65 . Since the $i$ is chosen independently for $\operatorname{SLE}_{65(i)}^{1}$ and $\mathrm{SLE}_{65(\mathrm{i})}^{2}$, the sample distribution of $\mathrm{z}$ can be computed as:

$$
z(i)=\frac{\operatorname{SLE}_{65(\mathrm{i})}^{2}-\mathrm{SLE}_{65(\mathrm{i})}^{1}-\sum_{i=1}^{n_{s}}\left(\mathrm{SLE}_{65(\mathrm{i})}^{2}-\mathrm{SLE}_{65(\mathrm{i})}^{1}\right) / n_{s}}{\sqrt{{\widehat{\sigma_{1}}}^{2}+{\widehat{\sigma_{2}}}^{2}}}
$$

$i=1, \ldots, n_{s}$ where ${\widehat{\sigma_{1}}}^{2}$ and ${\widehat{\sigma_{2}}}^{2}$ can be computed from the sample distributions as:

$$
{\widehat{\sigma_{m}}}^{2}=\frac{\sum_{i=1}^{n_{s}}\left[\mathrm{SLE}_{65(\mathrm{i})}^{h}-\sum_{i=1}^{n_{s}} \operatorname{SLE}_{65(\mathrm{i})}^{h} / n_{s}\right]^{2}}{n_{s}-1} ; m=1,2
$$

Using the sample distribution of $z$, we can find out the $95 \%$ confidence interval, namely $\left[c_{1}, c_{2}\right]$, not exactly but approximately. The test statistic of the observed value $z$ is

$$
z=\frac{\mathrm{LE}_{65}^{2}-\mathrm{LE}_{65}^{1}}{\sqrt{{\widehat{\sigma_{1}}}^{2}+{\widehat{\sigma_{2}}}^{2}}}
$$

where ${\widehat{\sigma_{1}}}^{2}$ and ${\widehat{\sigma_{2}}}^{2}$ are the estimated variances of $\mathrm{LE}_{65}^{1}$ and $\mathrm{LE}_{65}^{2}$, which can be computed from the sample distributions as above.

If $z$ falls outside $\left[c_{1}, c_{2}\right]$, then the null hypothesis leads to an observation that occurs with a probability smaller than 0.05 , and hence it is rejected at the 0.05 level. Moreover, if the test is a one-tailed test to the right, then for a given significance level we can calculate the critical value $Z_{\alpha}$ using the sample distribution of $\mathrm{z}$ such that $\operatorname{Pr}\left(z \leq Z_{\alpha}\right)=1-\alpha$

11 https://sites.google.com/site/carlogiovannicamarda/r-stuff/life-expectancy-confidence-interval. In this process we use the function $r$ binom $\left(\mathrm{m} \cdot n s, N t i l, q_{x}\right)$ to generate life table deaths, $\mathrm{Y}$, where $\mathrm{m}$ are the number of ages (65 to 101), ns the number of random samples, in this case 1,000, Ntil $=\operatorname{round}\left(D_{x} / q_{x}\right)$, where $D_{x}$ is the number of observed deaths and $q_{x}$ the smoothed observed probabilities of death. Then we construct the simulated probabilities, $Q_{x}=Y / N t i l$, to be used to generate simulated life tables and, as a product of the $n s$, simulated life expectancies at a given age, $\mathrm{SLE}_{\mathrm{X}(\mathrm{i})}, i=1, \ldots, n_{s}$. Using the sample distribution of these $n_{s}$ replicates we construct the confidence interval at a given quantile. 
The main results of using this alternative methodology are shown in the following tables. The robustness of the results is assured given that they are almost identical to what was seen in section 3 .

\begin{tabular}{|l|c|c|c|}
\hline \multicolumn{4}{|c|}{ Table A1: Critical values right-tailed test for $\mathbf{z}$ score between pension regime groups } \\
\hline \multicolumn{1}{|c|}{ DLE $_{65}$ between SE and PE } \\
\hline Items & P1 & P2 & P3 \\
\hline $5 \%$ significance level & 2.346 & 2.234 & 2.443 \\
\hline $10 \%$ significance level & 1.573 & 1.647 & 1.725 \\
\hline \multicolumn{5}{|c|}{1.322} & 1.275 & 1.304 \\
\hline $1 \%$ significance level & DLE $_{75}$ between SE and PE & 2.396 \\
\hline $5 \%$ significance level & 2.229 & 2.281 & 1.659 \\
\hline $10 \%$ significance level & 1.631 & 1.684 & 1.279 \\
\hline \multicolumn{4}{|c|}{ Source: Own work } \\
\hline
\end{tabular}

Table A2: Absolute differences in life expectancy between pension regime groups

\begin{tabular}{|c|c|c|c|}
\hline \multirow{2}{*}{ Items } & \multicolumn{3}{|c|}{ Dif. between SE and PE } \\
\hline & $\mathbf{P}_{1}$ & $\mathbf{P}_{2}$ & $\mathbf{P}_{3}$ \\
\hline $\operatorname{DLE}_{65}$ & 0.232 & 0.539 & 0.546 \\
\hline $\operatorname{Se}\left(\operatorname{DLE}_{65}\right)$ & 0.164 & 0.155 & 0.122 \\
\hline z score & $1.41^{*}$ & $3.45^{* * *}$ & $3.61^{* * *}$ \\
\hline $\mathrm{DLE}_{75}$ & 0.098 & 0.427 & 0.337 \\
\hline $\operatorname{Se}\left(\mathrm{DLE}_{75}\right)$ & 0.144 & 0.132 & 0.132 \\
\hline z score & 0.69 & $3.15^{* * *}$ & $2.54^{* * *}$ \\
\hline \multicolumn{4}{|c|}{$\begin{array}{l}\text { *** significant at } 1 \% \text { one-tailed test. }{ }^{* *} \text { significant at } 5 \% \text { one-tailed test. }{ }^{*} \text { significant at } 10 \% \text { one } \\
\text { tailed test. }\end{array}$} \\
\hline
\end{tabular}

Table A2 is the equivalent to Table 4 shown in section 3.

\begin{tabular}{|l|c|c|c|c|c|c|}
\hline \multicolumn{7}{|c|}{ Table A3. Critical values right-tailed test for $z$ score within pension regime groups } \\
between periods \\
\hline \multicolumn{7}{|c|}{ DLE } \\
\hline \multirow{2}{*}{ Items } & PE & \multicolumn{2}{c|}{ SE } & \multicolumn{2}{c|}{ PE+SE } \\
\cline { 2 - 7 } & P2-P1 & P3-P2 & P2-P1 & P3-P2 & P2-P1 & P3-P2 \\
\hline $1 \%$ significance level & 2.166 & 2.348 & 2.246 & 2.386 & 2.235 & 2.199 \\
\hline $5 \%$ significance level & 1.563 & 1.579 & 1.571 & 1.572 & 1.659 & 1.719 \\
\hline $10 \%$ significance level & 1.212 & 1.268 & 1.224 & 1.211 & 1.356 & 1.279 \\
\hline \multicolumn{7}{|c|}{ DLE $_{75}$} \\
\hline $1 \%$ significance level & 2.327 & 2.356 & 2.070 & 2.315 & 2.265 & 2.240 \\
\hline $5 \%$ significance level & 1.642 & 1.587 & 1.537 & 1.572 & 1.622 & 1.631 \\
\hline $10 \%$ significance level & 1.272 & 1.217 & 1.194 & 1.197 & 1.318 & 1.256 \\
\hline \multicolumn{7}{|c|}{ Source: Own work } \\
\hline
\end{tabular}




\begin{tabular}{|c|c|c|c|c|c|c|}
\hline \multicolumn{7}{|c|}{$\begin{array}{c}\text { Table A4: Absolute differences in life expectancy within pension regime groups by } \\
\text { periods }\end{array}$} \\
\hline \multirow{2}{*}{ Items } & \multicolumn{2}{|c|}{ PE } & \multicolumn{2}{|c|}{ SE } & \multicolumn{2}{|c|}{$\mathrm{PE}+\mathrm{SE}$} \\
\hline & $\mathbf{P}_{2}-\mathbf{P}_{1}$ & $\mathbf{P}_{3}-\mathbf{P}_{2}$ & $\mathbf{P}_{2}-\mathbf{P}_{1}$ & $\mathbf{P}_{3}-\mathbf{P}_{2}$ & $\mathbf{P}_{2}-\mathbf{P}_{1}$ & $\mathbf{P}_{3}-\mathbf{P}_{2}$ \\
\hline $\mathrm{DLE}_{65}$ & 0.346 & 0.297 & 0.653 & 0.304 & 0.463 & 0.278 \\
\hline $\operatorname{Se}\left(\mathrm{DLE}_{65}\right)$ & 0.128 & 0.126 & 0.185 & 0.176 & 0.106 & 0.103 \\
\hline z score & $2.69^{* * *}$ & $2.38^{* * *}$ & $3.50^{* * *}$ & $1.71^{* *}$ & $4.38^{* * *}$ & $2.72^{* * *}$ \\
\hline $\mathrm{DLE}_{75}$ & 0.291 & 0.338 & 0.619 & 0.248 & 0.425 & 0.278 \\
\hline $\operatorname{Se}\left(\mathrm{DLE}_{75}\right)$ & 0.114 & 0.113 & 0.158 & 0.148 & 0.095 & 0.092 \\
\hline z score & $2.59^{* * *}$ & $3.03^{* * *}$ & $3.84^{* * *}$ & $1.62^{*}$ & $4.60^{* * *}$ & $3.08^{* * *}$ \\
\hline \multicolumn{7}{|c|}{$\begin{array}{l}* * * \text { significant at } 1 \% \text { one-tailed test. }{ }^{* *} \text { significant at } 5 \% \text { one-tailed test. }{ }^{*} \text { significant at } 10 \% \text { one } \\
\text { tailed test. }\end{array}$} \\
\hline \multicolumn{7}{|c|}{ Source: Own work } \\
\hline
\end{tabular}

Table A4 is the equivalent to Table 5 shown in section 3.

\begin{tabular}{|c|c|c|c|c|c|c|}
\hline \multicolumn{7}{|c|}{ Table A5: Critical values right-tailed test for $\mathrm{z}$ score between PI groups by periods } \\
\hline \multicolumn{7}{|c|}{$\mathrm{DLE}_{65}$} \\
\hline \multirow[t]{2}{*}{ Items } & \multicolumn{3}{|c|}{$\begin{array}{c}\text { Between High and low PI } \\
\text { groups } \\
(\mathrm{PE})\end{array}$} & \multicolumn{3}{|c|}{$\begin{array}{c}\text { Between Med-Low and low PI } \\
\text { groups } \\
\text { (SE) }\end{array}$} \\
\hline & $\mathbf{P}_{1}$ & $\mathbf{P}_{2}$ & $\mathbf{P}_{3}$ & $\mathbf{P}_{1}$ & $\mathbf{P}_{2}$ & $\mathbf{P}_{3}$ \\
\hline $1 \%$ sign. level & 2.340 & 2.303 & 2.300 & 2.515 & 2.414 & 2.316 \\
\hline $5 \%$ sign. level & 1.699 & 1.588 & 1.605 & 1.658 & 1.685 & 1.724 \\
\hline $10 \%$ sign. level & 1.317 & 1.227 & 1.194 & 1.255 & 1.291 & 1.334 \\
\hline \multicolumn{7}{|c|}{$\mathrm{DLE}_{75}$} \\
\hline $1 \%$ sign. level & 2.368 & 2.218 & 2.172 & 2.316 & 2.600 & 2.313 \\
\hline $5 \%$ sign. level & 1.670 & 1.593 & 1.610 & 1.660 & 1.783 & 1.744 \\
\hline $10 \%$ sign. level & 1.354 & 1.236 & 1.292 & 1.327 & 1.278 & 1.290 \\
\hline \multicolumn{7}{|c|}{ Source: Own work } \\
\hline
\end{tabular}

\begin{tabular}{|c|c|c|c|c|c|c|}
\hline \multicolumn{7}{|c|}{ Table A6: Absolute differences in life expectancy between PI groups by periods and age } \\
\hline \multirow[t]{2}{*}{ Items } & \multicolumn{3}{|c|}{$\begin{array}{c}\text { Between High and low PI } \\
\text { groups } \\
(\mathrm{PE})\end{array}$} & \multicolumn{3}{|c|}{$\begin{array}{c}\text { Between Med-Low and low PI } \\
\text { groups } \\
\text { (SE) }\end{array}$} \\
\hline & $\mathbf{P}_{1}$ & $\mathbf{P}_{2}$ & $\mathbf{P}_{3}$ & $\mathbf{P}_{1}$ & $\mathbf{P}_{2}$ & $\mathbf{P}_{3}$ \\
\hline $\mathrm{DLE}_{65}$ & 1.367 & 1.150 & 1.960 & 0.459 & 1.202 & 0.520 \\
\hline $\operatorname{Se}\left(\mathrm{DLE}_{65}\right)$ & 0.817 & 0.342 & 0.330 & 0.237 & 0.326 & 0.326 \\
\hline z score & $3.94^{* * *}$ & $3.34^{* * *}$ & $5.95^{* * *}$ & $1.37^{*}$ & $3.57^{* * *}$ & $1.61^{*}$ \\
\hline $\mathrm{DLE}_{75}$ & 0.452 & 0.433 & 0.830 & 0.284 & 0.694 & 0.295 \\
\hline $\operatorname{Se}\left(\mathrm{DLE}_{75}\right)$ & 0.309 & 0.309 & 0.303 & 0.253 & 0.253 & 0.261 \\
\hline z score & $1.48^{*}$ & $1.40^{*}$ & $2.76^{* * *}$ & 1.12 & $2.67^{* * *}$ & 1.07 \\
\hline \multicolumn{7}{|c|}{ 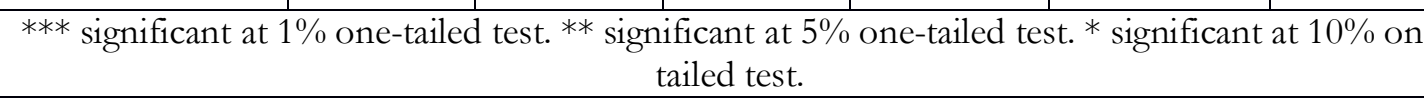 } \\
\hline \multicolumn{7}{|c|}{ Source: Own work } \\
\hline
\end{tabular}

Table A6 is the equivalent to Table 6 shown in section 3. 


\begin{tabular}{|c|c|c|c|c|c|c|}
\hline \multicolumn{7}{|c|}{ Table A7: Critical values right-tailed test for $\mathrm{z}$ score between PI groups by periods } \\
\hline \multirow{3}{*}{ Items } & \multicolumn{3}{|c|}{$\mathrm{DLE}_{65}$} & \\
\hline & \multicolumn{3}{|c|}{$\begin{array}{l}\text { Between Low groups } \\
\text { (SE-PE) }\end{array}$} & \multicolumn{3}{|c|}{$\begin{array}{c}\text { Between Med-Low groups } \\
\text { (SE-PE) }\end{array}$} \\
\hline & $\mathbf{P}_{1}$ & $\mathbf{P}_{2}$ & $\mathbf{P}_{3}$ & $\mathbf{P}_{1}$ & $\mathbf{P}_{2}$ & $\mathbf{P}_{3}$ \\
\hline $1 \%$ sign. level & 2.301 & 2.170 & 2.122 & 2.165 & 2.528 & 2.136 \\
\hline $5 \%$ sign. level & 1.538 & 1.591 & 1.640 & 1.631 & 1.681 & 1.610 \\
\hline $10 \%$ sign. level & 1.231 & 1.301 & 1.276 & 1.270 & 1.332 & 1.231 \\
\hline \multicolumn{7}{|c|}{ DLE $_{75}$} \\
\hline $1 \%$ sign. level & 2.245 & 2.290 & 2.398 & 2.265 & 2.349 & 2.277 \\
\hline $5 \%$ sign. level & 1.529 & 1.561 & 1.605 & 1.663 & 1.711 & 1.513 \\
\hline $10 \%$ sign. level & 1.227 & 1.275 & 1.233 & 1.243 & 1.301 & 1.215 \\
\hline \multicolumn{7}{|c|}{ Source: Own work } \\
\hline
\end{tabular}

Table A8: Absolute differences in life expectancy between pension regime groups by equivalent pension income groups and periods

\begin{tabular}{|c|c|c|c|c|c|c|}
\hline \multirow{2}{*}{ Items } & \multicolumn{3}{|c|}{$\begin{array}{l}\text { Between Low groups } \\
\text { (SE-PE) }\end{array}$} & \multicolumn{3}{|c|}{$\begin{array}{l}\text { Between Med-Low groups } \\
\text { (SE-PE) }\end{array}$} \\
\hline & $\mathbf{P}_{1}$ & $\mathbf{P}_{2}$ & $\mathbf{P}_{3}$ & $\mathbf{P}_{1}$ & $\mathbf{P}_{2}$ & $\mathbf{P}_{3}$ \\
\hline $\operatorname{DLE}_{65}$ & 0.597 & 0.246 & 1.180 & 0.665 & 1.057 & 1.113 \\
\hline $\operatorname{Se}\left(\mathrm{DLE}_{65}\right)$ & 0.386 & 0.389 & 0.386 & 0.213 & 0.195 & 0.187 \\
\hline z score & $1.56^{* *}$ & 0.62 & $3.00^{* * *}$ & $3.08^{* * *}$ & $5.38^{* * *}$ & $5.87^{* * *}$ \\
\hline $\operatorname{DLE}_{75}$ & -0.017 & 0.099 & 0.385 & 0.470 & 0.837 & 0.720 \\
\hline $\operatorname{Se}\left(\mathrm{DLE}_{75}\right)$ & 0.287 & 0.305 & 0.324 & 0.195 & 0.171 & 0.161 \\
\hline z score & -0.06 & 0.32 & 1.15 & $2.44^{* * *}$ & $4.86^{* * *}$ & $4.41^{* * *}$ \\
\hline \multicolumn{7}{|c|}{$\begin{array}{l}* * * \text { significant at } 1 \% \text { one-tailed test. }{ }^{* *} \text { significant at } 5 \% \text { one-tailed test. } * \text { significant at } 10 \% \text { one } \\
\text { tailed test. }\end{array}$} \\
\hline \multicolumn{7}{|c|}{ Source: Own work } \\
\hline
\end{tabular}

Table A8 is the equivalent to Table 7 shown in section 3. 